PNL-6952

UC-41

\title{
Hanford Radiological Protection Support Services Annual Report for 1988
}
M. Lyon
J. J. Fix
J. L. Kenoyer
J. A. Leonowich
H. E. Palmer
M. J. Sula

June 1989

Prepared for the U.S. Department of Energy under Contract DE-AC06-76RLO 1830

Pacific Northwest Laboratory Operated for the U.S. Department of Energy by Battelle Memorial Institute

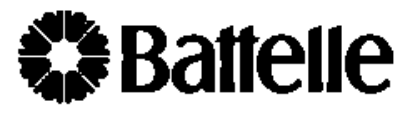




\title{
DISCLAIMER
}

This program was prepared as an account of work sponsored by an agency of the United States Government. Neither the United States Government nor any agency thereof, nor Battelle Memorial Institute, nor any of their employees, makes any warranty, express or implied, or assumes any lega liability or responsibility for the accuracy, completeness, of usefulness of any information, apparatus, product, or process disclosed, or represents that its use would not intringe privately owned rights. Reference herein to any specific commerical product, process, or service by trade name, trademark, manufacturer, or otherwise, does not necessarily constitute or imply its endorsement, recommendation, or favoring by the United States Government or any agency thereof, or Battelle Memorial Institute. The views and opinions of authors expressed herein do not necessarily state or reflect those of the United States Government or any agency thereof.

\section{PACIFIC NORTHWEST LABORATORY operated by \\ BATTELLE MEMORIAL INSTITUTE for the \\ UNITED STATES DEPARTMENT OF ENERGY \\ under Contract DE-ACO6-76RLO 1830}

\author{
Printed in the United States of America \\ Available from \\ National Technical Information Service \\ United States Department of Commerce \\ 5285 Por Royal Road \\ Springfield, Virginia 22161 \\ NTIS Price Codes \\ Microfiche A01 \\ Printed Copy
}

$\begin{array}{cc}\text { Pages } & \begin{array}{c}\text { Price } \\ \text { Codes }\end{array} \\ 001-025 & \text { A02 } \\ 026-050 & \text { A03 } \\ 051-075 & \text { A04 } \\ 076-100 & \text { A05 } \\ 101-125 & \text { A06 } \\ 126-150 & \text { A07 } \\ 151-175 & \text { A08 } \\ 176-200 & \text { A09 } \\ 201-225 & \text { A10 } \\ 226-250 & \text { A11 } \\ 251-275 & \text { A12 } \\ 276-300 & \text { A13 }\end{array}$


PNL -6952

UC-41

HANFORD RADIOLOGICAL

PROTECTION SUPPORT SERVICES

ANNUAL REPORT FOR 1988

M. Lyon

J. J. Fix

J. L. Kenoyer

J. A. Leonowich

H. E. Palmer

M. J. Sula

June 1989

Prepared for

the U.S. Department of Energy

under Contract DE-AC06-76RL0 1830

Pacific Northwest Laboratory

Richland, Washington 99352 
! 


\section{SUMMARY}

This report documents the performance of certain radiological protection sitewide services during calendar year (CY) 1988 by Pacific Northwest Laboratory (PNL) (a) in support of the U.S. Department of Energy-Richland Operations Office (DOE-RL) and contractor activities on the Hanford Site. The routine program for each service is discussed along with any significant program changes and tasks, investigations, and studies performed in support of each program. Other related activities such as publications, presentations, and memberships on standards or industry committees are also listed. The programs covered provide services in the areas of 1) internal dosimetry, 2) in vivo measurements, 3) external dosimetry, 4) instrument calibration and evaluation, 5) calibration of radiation sources traceable to the National Institute of Standards and Technology (NIST) (formerly the National Bureau of Standards), and 6) radiological records.

During 1988, the Internal Dosimetry Program performed 13,616 bioassay measurements. Seventy-two assessments of potential new intakes, along with 8 reassessments of prior exposures, were performed. Quality control monitoring of the bioassay analytical services laboratory continued, showing generally satisfactory performance except in two instances. During the year, a new contract was negotiated with the analytical services laboratory and a new Statement of Work for CY 1989 was developed. Supporting tasks performed included upgrades supporting the implementation of the new DOE Order 5480.11, Radiation Protection for Occupational Workers, evaluation of methods to improve routine bioassay monitoring of freshly separated and poorly transported plutonium, comparison of premortem and postmorten estimates of plutonium deposition, and continuation of the pilot fecal-sampling program that started last year.

The In Vivo Measurement Program provided a total of 8899 measurements during CY 1988. Changes to facilities and equipment included the addition of two shielded rooms, letting a contract to provide a new mobile counter unit, the addition of a large-volume germanium detector array, installation of an

(a) Pacific Northwest Laboratory is operated for the U.S. Department of Energy by Battelle Memorial Institute under Contract DE-AC06-76RLO 1830. 
improved support system for the planar germanium detectors, and the extension of the Hanford local area network to the program facilities. Special studies conducted and other changes incorporated included the calibration for skeletal content of radionuclides by measuring subjects with a known skeleton content of $133 \mathrm{Ba}, 92 \mathrm{mNb}$ studies for improving calibration factors for measuring 239Pu in the lung, provision of preliminary results to workers at the completion of a measurement, and the feasibility of operating a remote whole body counter.

The External Dosimetry Program transferred the sitewide dosimeter processing function to PNL and processed approximately 90,000 dosimeters. Two new automated dosimeter readers were incorporated into the program. Other activities included the voluntary inclusion of Hanford basic, multipurpose, and beta/photon dosimeters in performance testing under the DOE Laboratory Accreditation Program; intercomparison testing of PNL, Washington Public Power Supply System, Washington State, and Oregon State environmental dosimeters; field measurements conducted at the Plutonium Uranium Extraction Plant and the Plutonium Finishing Plant; and laboratory and field evaluation of a prototype CR-39/Hanford albedo combination dosimeter. Five external dosimetry issues involving reporting shallow dose for basic dosimeters, environmental background correction, accredited dosimeters for supplemental dosimetry, zero reported dose, and changes to individual dose records were submitted to and formally reviewed by the Hanford Personnel Dosimetry Advisory Committee.

The Instrument Calibration and Evaluation Program procured new portable instruments to replace damaged or discarded instruments and tested new pocket alarming dosimeters for field deployment. The Hanford Instrument Evaluation Program received and evaluated new ion-chamber instruments for field use at Hanford. New FY 1987 ionization chambers were deployed in the field and FY 1985 models were upgraded. The practice of calibrating instruments for Westinghouse Hanford Company was also initiated. Tasks performed during the year that supported the routine program included calibrating a portion of the alpha continuous air monitors and installing natural uranium check sources into Eberline Geiger-Mueller instruments. In the area of program 
documentation, the instrument manual was updated and preparation of an instrument calibration historical report was initiated.

Improvements to the Radiation Standards and Calibrations Project during 1988 included the lease of a new 252Cf source for the pneumatic transfer system and the redesign of the north irradiation station in Room 6. Changeover to the HP-9000 computer was completed, providing a major improvement in data handling for the project. Software was upgraded and modified as required. Supporting investigations and studies conducted during the year included measurement quality assurance for photon beams, Monte Carlo simulations on the energy spectrum of the 252Cf source, and further evaluation of instrument bar code labels.

During the year the Radiological Records Program operated the occupational radiation exposure (ORE) system and the Hanford Radiation Protection Historical Files in support of the DOE-RL and Hanford contractor radiological protection and dosimetry programs. Changes to these systems included the conversion of the ORE system to the new dose equivalent terminology, changes in the practice of recording certain neutron doses of less than $50 \mathrm{mrem}$, and the automatic loading of Radiation Exposure Information Reporting System occupationà 1 and facility codes into dosimeter result records. Tasks performed in support of the program included compiling a centralized historical file of Hanford radiological incidents, modifying the ORE system to enable contractors to access routine excreta schedules, and producing a preliminary plan for the redevelopment of the ORE system. 
' 


\section{ACRONYMS LIST}

$\begin{array}{ll}\text { ANSI } & \text { American National Standards Institute } \\ \text { CAM } & \text { continuous air monitor } \\ \text { CAR } & \text { computer-assisted retrieval } \\ \text { CP } & \text { cutie pie } \\ \text { CY } & \text { calendar year } \\ \text { DOE } & \text { U.S. Department of Energy } \\ \text { DOELAP } & \text { U.S. Oepartment of Energy Laboratory Accreditation } \\ & \text { Program } \\ \text { DOE-RL } & \text { U.S. Department of Energy-Richland Operations office } \\ \text { DSHS } & \text { Washington State Division of Social and Health Services } \\ \text { DTPA } & \text { diethylene triamine penta acetate } \\ \text { FY } & \text { fiscal year } \\ \text { GI } & \text { gastrointestinal } \\ \text { HBPD } & \text { Hanford beta/photon dosimeter } \\ \text { HEHF } & \text { Hanford Environmental Health Foundation } \\ \text { HMPD } & \text { Hanford multipurpose dosimeter } \\ \text { HRCP } & \text { high-range cutie pie } \\ \text { ICRP } & \text { International Commission on Radiological Protection } \\ \text { KEH } & \text { Kaiser Engineers Hanford } \\ \text { LANL } & \text { Los Alamos National Laboratory } \\ \text { MCA } & \text { multichannel analyzer } \\ \text { MDA } & \text { quality assurance } \\ \text { MPBB } & \text { minimum detectable activity } \\ \text { MQA } & \text { maximum permissible body burden } \\ \text { NIST } & \text { measurement quality assurance } \\ \text { ORE } & \text { National Institute of Standards and Technology } \\ \text { OSHD } & \text { Occupational Radiation Exposure } \\ \text { PFP } & \text { Oregon State Health Division } \\ \text { PNAD } & \text { Plutonium Finishing Plant } \\ \text { PNL } & \text { personal nuclear accident dosimeter } \\ \text { PROM } & \text { Pacific Northwest Laboratory } \\ \text { PUREX } & \text { programable read-only memory } \\ \text { QA } & \text { Plutonium Uranium Extraction (Plant) } \\ \end{array}$


QC

REIRS

RPS

RMC

SEE

SOW

TGLD

TRU

UST

USTR

$W B C$

WHC

WPPSS quality control

Radiation Exposure Information Reporting System

Radiation Protection Standard

Remote Mechanical Line $\mathrm{C}$

specific effective energy

Statement of Work

Task Group on Lung Dynamics

transuranic

United States Testing Company, Inc.

United Stated Transuranium Registry

Whole Body Counter

Westinghouse Hanford Company

Washington Public Power Supply System 


\section{ACKNOWLEDGMENTS}

The authors thank the staff members whose professional skills and technical expertise ensure the success of Hanford's External Dosimetry Program, Internal Dosimetry Program, In Vivo Measurement Program, Instrument Calibration and Evaluation Program, Radiation Standards and Calibrations Project, and Radiological Records Program. 


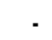




\section{CONTENTS}

SUMMARY $\ldots \ldots \ldots \ldots \ldots \ldots \ldots \ldots \ldots$

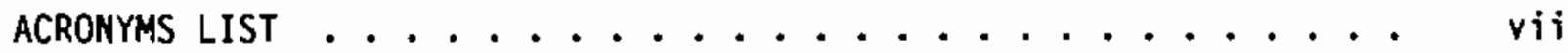

ACKNOWLEDGMENTS ......................... ix

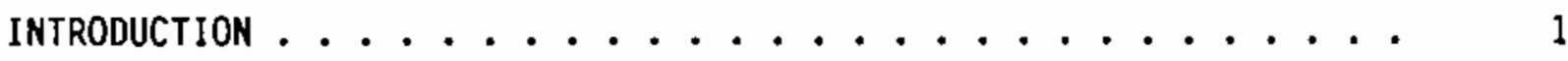

HANFORD INTERMAL DOSIMETRY PRDGRAM .............. 3

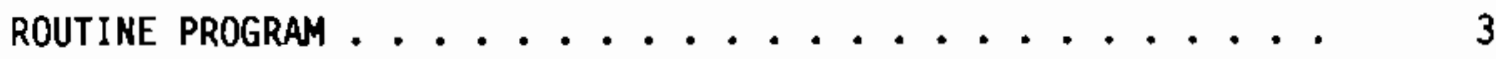

MONITORING AND ASSESSMENT ACTIVITIES ........... 6

Evaluation of a 1985 Plutonium Wound Case ....... 12

BIOASSAY ANALYTICAL SERVICES . . . . . . . . . 12

Laboratory Operational Requirements . . . . . . 12

Laboratory Quality Control ........... 13

SUPPORTING INVESTIGATIONS AND STUDIES ............ 14

Upgrades Supporting the Implementation of DOE 5480.11 . . 14

Evaluation of Methods to Improve Routine Bioassay

Monitoring for Freshly Separated, Poorly Transported

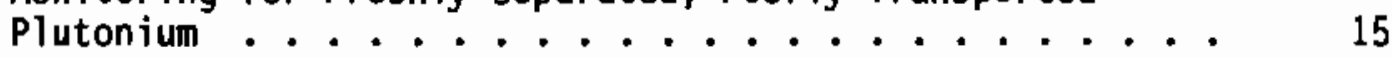

Pilot Fecal-Sampling Program ............ 16

Comparison of Premortem and Postmortem Estimates of

Plutonium Deposition............. 17

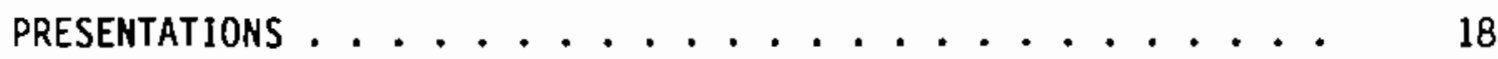

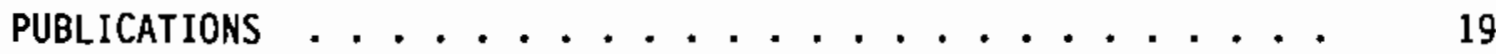

PROGRAM-RELATED PROFESSIONAL ACTIVITIES .......... 20

HANFORD IN VIVO MEASUREMENT PROGRAM ............... 21

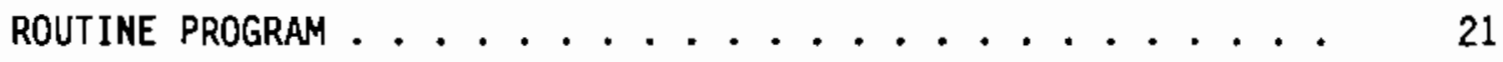

ADDITIONS OR CHANGES TO EQUIPMENT AND FACILITIES IN $1988 \ldots 22$

Construction of Two New Shielded Rooms . . . . . . 22 
Array of Large-Volume Germanium Detectors . . . . . . 25

New Support System for Planar Germanium Detectors . . . 27

New Mobile Whole Body Counter . . . . . . . . . 27

SPECIAL STUDIES CONDUCTED IN $1988 \ldots . \ldots 27$

Calibration for Skeletal Content of Radionuclides by

Measuring Subjects with Known Skeleton Contents of

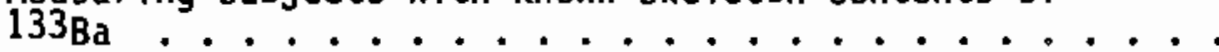

Niobium-92m Studies for Improving Calibration Factors

for Measuring 239pu in the Lung ..........

Preliminary Results Given to Workers at the Completion

of a Measurement..............

Feasibility of the Remote Operation of a

Whole Body Counter.............. 31

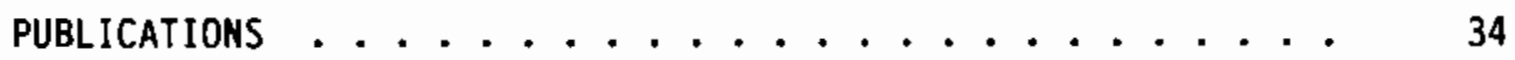

HANFORD EXTERMAL DOSIMETRY PROGRAM . . . . . . . . . . 37

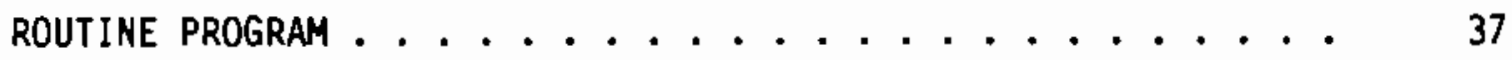

Reporting Shallow Dose............. 41

Correcting for Environmental Background ........ 41

Using Accredited Dosimeters for Supplemental Dosimetry . . 42

Reporting Zero Dose ............ 43

Making Changes to Individual Dose Records . . . . . . 44

SUPPORTING INVESTIGATIONS AND STUDIES ............ 44

Combination CR-39/Hanford Albedo Dosimeter ...... 44

Dosimeter Performance Testing .......... 45

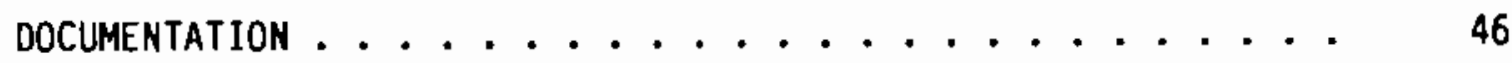

PRESENTATIONS ......................... 47

PROGRAM-RELATED PROFESSIONAL ACTIVITIES .......... 47 
INSTRUMENT CALIBRATION AND EVALUATION PROGRAM . . . . . . . . 49

ROUTINE PROGRAM ........................... 49

Routine Portable Instrument Pool . . . . . . . . 50

Hanford Instrument Evaluation Program ........ 50

Deployment of High-Range Cutie Pies .......... . 50

Instrument Manual Update . . . . . . . . . . 52

Documentation of the History of Hanford Instruments . . . 52

SUPPORTING TASKS ....................... 53

Alpha Continuous Air Monitor Calibration ........ 53

Pocket Alarming Dosimeters for the 200 Area

Fire Station.................... 54

Check Sources for EGM Instruments . . . . . . . . 54

PROGRAM-RELATED PROFESSIONAL ACTIVITIES . . . . . . . . 54

RADIATION STANDARDS AND CALIBRATIONS PROJECT . . . . . . . 55

ROUTINE PROGRAM ........................... 55

Maintenance of Standards and Capabilities ....... 55

Maintenance of the Data Management System . . . . . 57

SUPPORTING INVESTIGATIONS AND STUDIES ............ 58

Measurement Quality Assurance for Photon Beams . . . . . 58

Monte Carlo Simulations of Neutron Transport . . . . . 58

Evaluation of Instrument Bar Code Labels . . . . . . 59

HANFORD RADIOLOGICAL RECORDS PROGRAM . . . . . . . . . 61

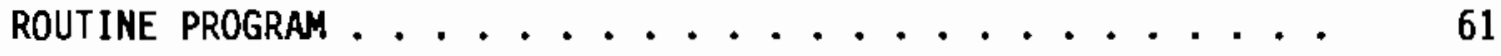

Changes to the Routine Program .......... 63

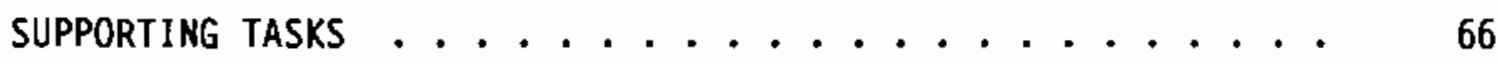

Redevelopment of the ORE System ......... 66 
Modifications to the ORE System - Excreta

Collection Addresses . . . . . . . . . . .

Centralization of the Hanford Radiological

Incident file ...............

REFERENCES ............................ 


\section{FIGURES}

1 Hanford Radiological Support Services Major Communication

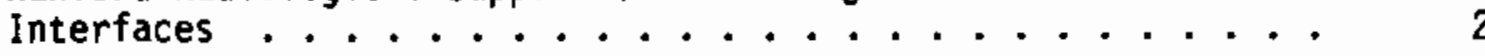

2 Routine Urine Measurements Recorded from 1986 Through 1988 . . 8

3 Routine In Vivo Measurements Recorded from 1986 Through 1988 . 9

4 Sumary of Contractor-Reported Incidents from 1986

Through $1988 \ldots \ldots \ldots \ldots . \ldots . \ldots$

5 Comparison of Premorten and Postmortem Estimates of

Plutonium in Skeleton and Liver.............

6 In Vivo Measurements Made at the Whole Body Counter, 1984 Through $1988 \ldots . \ldots . . . \ldots$

7 The Construction of the Footing for the Shielded Room Moved from the University of Utah . . . . . . . . . 24

8 The Assembly of the Walls of the Utah Shielded Room . . . . . 25

9 The Three-Detector Array for Whole and Partial Body Measurements in the Utah Shielded Room .......... 26

10 New Holders for the Planar Germanium Detectors . . . . . . 28

11 Supported Planar Germanium Detectors in Use on a Subject ... 29

12 "Preliminary Analysis of In Vivo Examination" Form Letter ... 31

13 Equipment Schematic for a Remotely Operated Whole Body Counter at the HS-1 Building .............. 35

14 Technician Using a Reader System ............ 38

15 Hanford Personal Nuclear Accident Dosimeter... . . . . . 40 


\section{$\underline{\text { TABLES }}$}

1 Specified Minimum Detectable Activities and Follow-Up

Level for Routine Urinalyses During 1988 . . . . . . . . . 4

2 Minimum Detectable Activities and Follow-Up Levels for In Vivo Measurements During $1987 \ldots \ldots$. . . . . . . 5

3 Models Used to Interpret Bioassay Data During $1988 \ldots \ldots 6$

4 Excreta Measurements Recorded in the ORE Database During $1988 \ldots \ldots \ldots \ldots \ldots . \ldots \ldots$

5 In Vivo Measurements Recorded in the ORE Database During 1988......................... 8

6 Summary of Potential Exposure Incidents During 1988 . . . . 10

7 Internal Dose Status of Hanford Horkforce at 1988 Yearend . . 11

8 Potentially Undetectable Doses from Intakes of Freshly Separated Weapons-Grade Plutonium Using Routine Bioassay Measurements. ..................... 15

9 Estimates of Plutonium in Skeleton and Liver ........ 18

10 Measurements Made on Personnel During 1988 ......... 22

11 Audit Dosimeters Processed During $1988 \ldots . . . . . . .39$

12 Design Features of the Hanford Personal Nuclear . . . . . . . . . . . . 39

13 Shallow- and Deep-Dose Performance Test Data ........ 46

14 Portable 1nstrument Usage for Calendar Year $1988 \ldots . . . .51$

15 Records Activity for Calendar Year 1988 . . . . . . . . 63 


\section{INTRODUCTION}

This annual report documents the calendar year (CY) 1988 activities of certain sitewide services operated by the Pacific Northwest Laboratory (PNL) for the U.S. Department of Energy-Richland Operations Office (DOE-RL) and the Hanford contractors. The programs covered provide services in the areas of 1) internal dosimetry, 2) in vivo measurements, 3) external dosimetry, 4) instrument calibration and evaluation, 5) calibration of radiation sources traceable to the National Institute of Standards and Technology (NIST) (formerly the National Bureau of Standards), and 6) radiological records. All of the services fall within the purview of PNL's Health Physics Department.

While some of the programs discussed in this report are involved in activities funded by other sources such as supplying in vivo measurement and instrument calibration services to private nuclear companies and site environmental dose measurements, only those activities funded by DOE-RL and the Hanford contractors are addressed. It should be noted that 1) the services provided to non-DOE-RL activities are performed only to the extent that they do not affect services to DOE and its contractors, and 2) these services provide funds that support the program and reduce the costs to DOE and the Hanford contractors (i.e., Westinghouse Hanford Company [WHC], Kaiser Engineers Hanford [KEH], Hanford Environmental Health Foundation [HEHF], and PNL).

Each Hanford program listed above is presented in a separate section of the report, which discusses the routine program, including any significant changes; investigations, studies, and tasks performed in support of the routine program; and other applicable activities such as publications, presentations, program-related professional memberships, and related external professional activities. Figure 1 is an organizational chart showing the PNL and DOE-RL management structure and communication interfaces for each PNLoperated program and the DOE-RL Safety and Environment Division. 


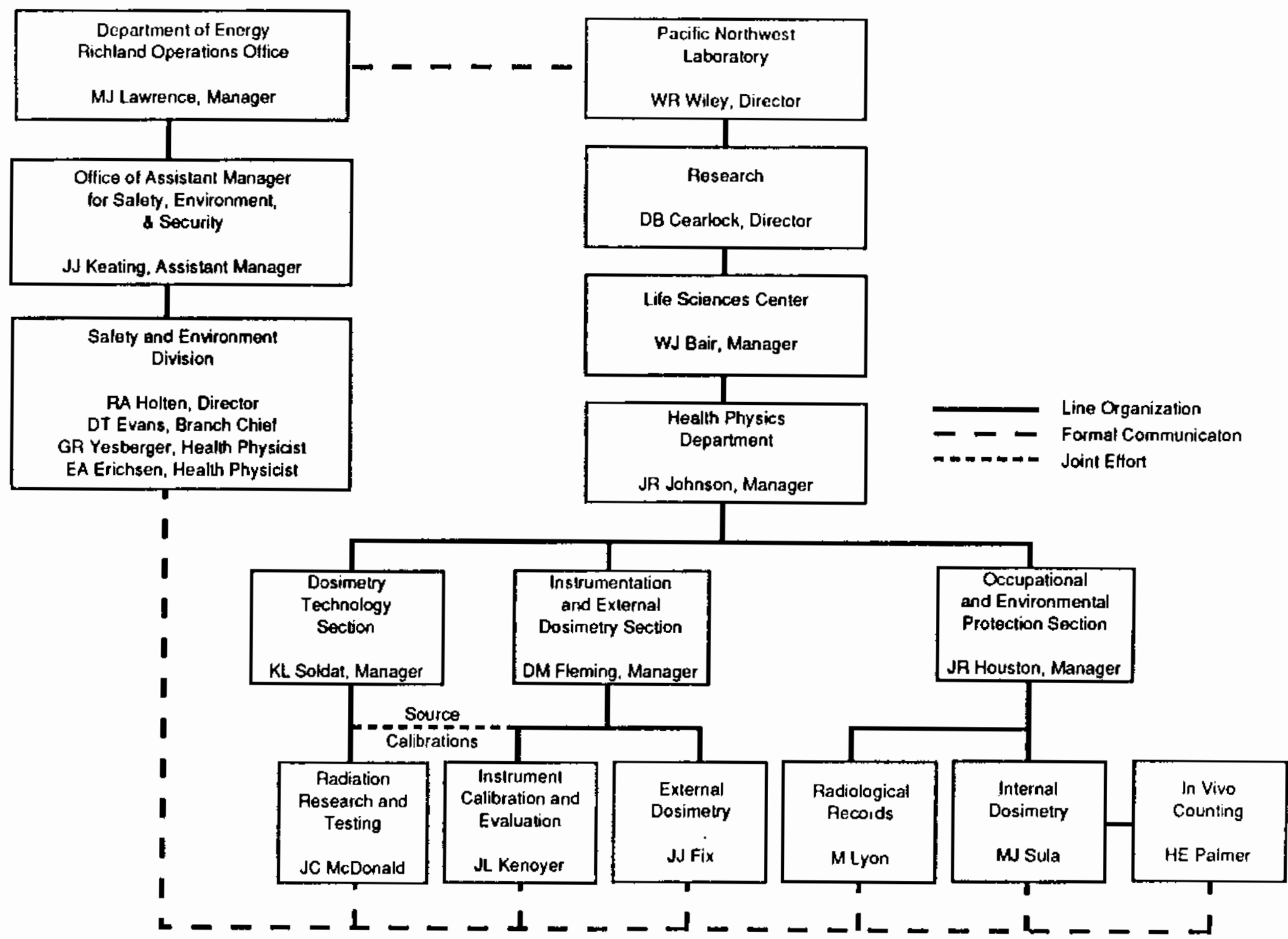

FIGURE 1. Hanford Radiological Support Services Major Communication Interfaces 
HANFORD INTERNAL DOSIMETRY PROGRAM

The Hanford Internal Dosimetry Program was initiated in late 1944 to assess and document occupational doses from intakes of radionuclides at Hanford. The program is administered in support of Hanford radiation protection programs as required by DOE 5480.1 (DOE 1981a) and the Hanford Site Services Handbook (DOE-RL 1983). The program provides the following internal dosimetry services:

- administration of a routine bioassay monitoring program

- investigation, assessment, and documentation of potential internal exposures

- monitoring of bioassay laboratory performance

- selection and application of models, procedures, and practices for evaluating internal exposures

- technical support to the DOE-RL and Hanford Site contractors.

ROUTINE PROGRAM

Bioassay monitoring is performed on a regular frequency for workers that could incur intakes of radionuclides on their job. Measurement types and frequencies are based on the radionuclides of concern and their anticipated physical and chemical form. Minimum detectable activities (MDAs) and followup levels for excreta and in vivo bioassay measurements are shown in Tables 1 and 2 ; respectively.

Intakes of radionuclides are generally prevented by containment or other protective measures. Internal exposures only occur as a result of the failure of a protective system. Exceptions to this are low-level chronic exposure conditions that exist for depleted and low-enrichment uranium in the 306-W Specialty Machine Shop, the Uranium 0xide Plant, and the $N$ Reactor Fuel Production Facility; and for tritium in several laboratories. In these facilities, internal exposures are controlled through engineered and administrative measures; however, because complete containment is not provided, lowlevel chronic exposures are assumed to occur. 
TABLE 1. Specified Minimum Detectable Activities and Follow-Up Levels for Routine Urinalyses During 1988

\begin{tabular}{|c|c|c|}
\hline Radionuclide & $\operatorname{MDA}(a)$ & $\begin{array}{l}\text { Follow-Up Level } \\
\text { sampling frequency }(b)\end{array}$ \\
\hline $90 \mathrm{Sr}$ & $2 \mathrm{dpm} / \mathrm{s}$ & $10 \mathrm{dpm} / \mathrm{s}(\mathrm{A})$ \\
\hline $238 \mathrm{Pu}$ & $0.02 \mathrm{dpm} / \mathrm{s}$ & $>M D A \quad(A)$ \\
\hline $239 \mathrm{Pu}$ & $0.02 \mathrm{dpm} / \mathrm{s}$ & $>$ MDA (A) \\
\hline $241_{\text {Am }}$ & $0.02 \mathrm{dpm} / \mathrm{s}$ & $>$ MDA (A) \\
\hline $244 \mathrm{~cm}$ & $0.02 \mathrm{dpm} / \mathrm{s}$ & $>M D A(A)$ \\
\hline U-natural & $0.2 \mu \mathrm{g} / \mathrm{L}$ & $5 \mu g / s(B W)$ \\
\hline U-natural & $0.07 \mu g / L(c)$ & $0.2 \mu \mathrm{g} / \mathrm{s}(\mathrm{Q}, \mathrm{A})(\mathrm{d})$ \\
\hline
\end{tabular}

(a) Specified MDA based on Type I and Type II errors of 5\% as described in the "1987 Statement of Work for the Fifth Operational Year of Analytical Services of Subcontract B-2472-A-I" except for the noted U-natural measurement, which is given as the actual achieved MDA for fiscal year (FY) 1988.

(b) Investigation of a potential internal exposure is performed whenever these values are exceeded. Routine bioassay monitoring frequency: A-annual, Q-quarterly, M-monthly, BW-biweekly.

(c) Actual achieved MDA for FY 1988 based on evaluation of quality control data by Bihl (Bihl, D. E. 1989.

Results of the Bioassay Audit Program for Fiscal Year 1989. Copy in the Hanford Radiation Protection Historical Files, Pacific Northwest Laboratory, Richland, Washington).

(d) Upper level of expected environmentally derived uranium in urine for the Hanford region.

Assessments of internal dose are performed for intakes potentially exceeding 18 of the DOE Radiation Protection Standard (RPS) in DOE 5480.11 (DOE 1989). Internal dose assessments are performed using biokinetic models to interpret bioassay measurements. The standardized biokinetic models used are listed in Table 3. The dose conversion factors are consistent with the specific effective energy (SEE) values in Publication 30 of the International Commission on Radiological Protection (ICRP 1979) except that a quality factor of 10 instead of 20 is used for alpha particles. The quality factor of 10 was mandated by DOE 5480.1, Chapter XI (DOE 1981a). The biokinetic 
TABLE 2. Minimum Detectable Activities and Follow-Up Levels for In Vivo Measurements During 1987

Measurement-Radionuclide(a)

Whole Body Count

$22 \mathrm{Na}$
$54 \mathrm{Mn}$
$59 \mathrm{Fe}$
$60 \mathrm{Co}$
$106 \mathrm{Ru}$
$154 \mathrm{Eu}$
$137 \mathrm{Cs}$
$95 \mathrm{Zr}$

\section{Lung Count}

$144 \mathrm{Ce}$

154 Eu

$232 \mathrm{Th}$

$235 \mathrm{v}$

$238 \mathrm{U}(234 \mathrm{Th})$

238Pu

$239 \mathrm{Pu}$

$241_{\text {Am }}$
MDA, $n C i$

Follow-Up Level (b)

\section{5}

3

6

3

12

4.5

3

3
Det. Activity

$6 \mathrm{nCi}$

Det. Activity

$5 \mathrm{nCi}$

Det. Activity

Det. Activity

$6 \mathrm{nCi}$

Det. Activity
0.6
$3 \mathrm{nCi}$
0.07
$1.6 \mathrm{nCi}$
0.57
Det. Activity
0.12
Oet. Activity
1.8
Det. Activity
30
Det. Activity
Det. Activity
0.18

75

(a) For selected radionuclides. Oetection of radionuclides not listed results in follow-up investigation.

(b) Investigation of a potential internal exposure is performed whenever the follow-up level is exceeded. Calculated levels are based on the assumption of intake at the investigation level, assuming a mixture of fission and activation products. Others are based on the desire to investigate any positive measurement. 
TABLE 3. Models Used to Interpret Bioassay Data During 1988

\begin{tabular}{|c|c|}
\hline System & Model \\
\hline Respiratory tract & TGLD(a) Model (ICRP 1979) \\
\hline GI (b) tract & ICRP GI Tract Model (ICRP 1979) \\
\hline Pu urine excretion & Jones' Function (Jones 1985) \\
\hline $\begin{array}{l}\text { Sr urine excretion } \\
\text { Other metabolic models }\end{array}$ & $\begin{array}{l}\text { Dolphin-Eve Function (Dolphin and Eve 1963) } \\
\text { ICRP } 30 \text { (1979) }\end{array}$ \\
\hline
\end{tabular}

(a) TGLD = Task Group on Lung Dynamics.

(b) gastrointestinat.

models are implemented using the computer codes GENMOD, Version 3.0, (Johnson and Carver 1981) and PUCALC, Version 2.0.

Practices and procedures for internal dosimetry are described in PNL's internal procedures for dosimetry evaluations at Hanford. Bioassay measurement results are maintained in the occupational radiation exposure (ORE) database, and laboratory analytical procedures are documented in PNL's internal procedures for whole body counting and in the Procedures for Contract 002472-A-M(a) of the United States Testing Company, Inc. (UST). Assessments of internal dose are documented in the personal radiation exposure files of the ORE database.

MONITORING AND ASSESSMENT ACTIVITIES

During $C Y 1988,13,615$ bioassay measurements were performed and recorded in support of Hanford activities. Of these, 98\% were classified as routine and $2 \%$ were classified as special purpose measurements.(b) Tables 4 and 5 , respectively, sumarize the types and numbers of routine urine and in vivo bioassays recorded in the ORE database during 1988. Figures 2 and 3 compare

(a) United States Testing Company, Inc. 1989. Procedures for Contract $002472-A-M$. Richland, Washington.

(b) Fecal samples were collected and analyzed for plutonium on a routine schedule during 1988 as part of a pilot fecal-sampling program discussed later in this section. 
TABLE 4. Excreta Measurements Recorded in the ORE Database During 1988

\begin{tabular}{|c|c|c|c|c|c|}
\hline Type/Reason & DOE & KEH & PNL & WHC & Total \\
\hline \multicolumn{6}{|l|}{$3 \mathrm{H}$-urine } \\
\hline Routine schedule & 0 & 0 & 39 & & \\
\hline Special request & 0 & 0 & 0 & 0 & 0 \\
\hline Intake follow-up & 0 & 0 & 2 & 0 & 2 \\
\hline \multicolumn{6}{|l|}{90 Sr-urine } \\
\hline Rout ine schedule & 0 & 330 & 6 & 1020 & 1356 \\
\hline Special request & 0 & 0 & 0 & 4 & 4 \\
\hline Intake follow-up & 0 & 3 & 0 & 8 & 11 \\
\hline \multicolumn{6}{|l|}{ Uranium-urine } \\
\hline Routine schedule & 0 & 1 & 158 & 526 & 685 \\
\hline Special request & 0 & 0 & 1 & 1 & 2 \\
\hline Intake follow-up & 0 & 0 & 5 & 3 & 8 \\
\hline \multicolumn{6}{|l|}{ Plutonium(a)-urine } \\
\hline Routine schedule & 0 & 317 & 158 & 1533 & 2008 \\
\hline Special request & 0 & 0 & 2 & 71 & 73 \\
\hline Intake follow-up & 0 & 7 & 13 & 37 & 57 \\
\hline \multicolumn{6}{|l|}{ Plutonium-fecal } \\
\hline Rout ine schedule & 0 & 0 & 1 & 358 & 359 \\
\hline Special request & 0 & 0 & 14 & 11 & 25 \\
\hline Intake follow-up & 0 & 0 & 0 & 9 & 9 \\
\hline \multicolumn{6}{|l|}{ Other TRU(b)-urine } \\
\hline Rout ine schedule & 0 & 1 & 23 & 13 & 37 \\
\hline Special request & 0 & 0 & 3 & 0 & 3 \\
\hline Intake follow-up & 0 & 4 & 9 & 15 & 28 \\
\hline \multicolumn{6}{|l|}{ Other TRU(b)-fecal } \\
\hline Routine schedule & 0 & 0 & $\mathbf{0}$ & 0 & 0 \\
\hline \multirow{3}{*}{$\begin{array}{l}\text { Special request } \\
\text { Intake follow-up }\end{array}$} & 0 & 0 & 0 & 0 & 0 \\
\hline & $\underline{\underline{T}}$ & & & & \\
\hline & 0 & 663 & 435 & 3610 & 4708 \\
\hline
\end{tabular}

(a) Plutonium-239 and 239pu.

(b) Other transuranic elements (TRU) include $241_{\mathrm{Am}}, 242 \mathrm{Am}, 242 \mathrm{Cm}$, and $244 \mathrm{~cm}$. 
TABLE 5. In Vivo Measurements Recorded in the ORE Database During 1988

\begin{tabular}{|c|c|c|c|c|c|}
\hline \multirow{2}{*}{ Type/Reason } & \multirow{2}{*}{\multicolumn{5}{|c|}{$\begin{array}{l}\text { Number by Organization } \\
\text { KEH }\end{array}$}} \\
\hline & & KEH & $\mathrm{PNL}$ & WHC & Total \\
\hline \multicolumn{6}{|l|}{ Whole Body Count } \\
\hline Routine schedule & 23 & 1198 & 1098 & 4874 & 7193 \\
\hline Special request & 0 & 1 & 5 & 16 & 22 \\
\hline \multirow[t]{2}{*}{ Intake follow-up } & $\underline{0}$ & 14 & 4 & 10 & 28 \\
\hline & 23 & 1213 & 1107 & 4900 & 7243 \\
\hline \multicolumn{6}{|l|}{ Chest Count } \\
\hline Routine schedule & 0 & 221 & 195 & 1209 & 1625 \\
\hline Special request & 0 & 0 & 3 & 3 & 6 \\
\hline \multirow[t]{2}{*}{ Intake follow-up } & $\underline{0}$ & 5 & 6 & 22 & 33 \\
\hline & 0 & 226 & 204 & 1234 & 1664 \\
\hline
\end{tabular}

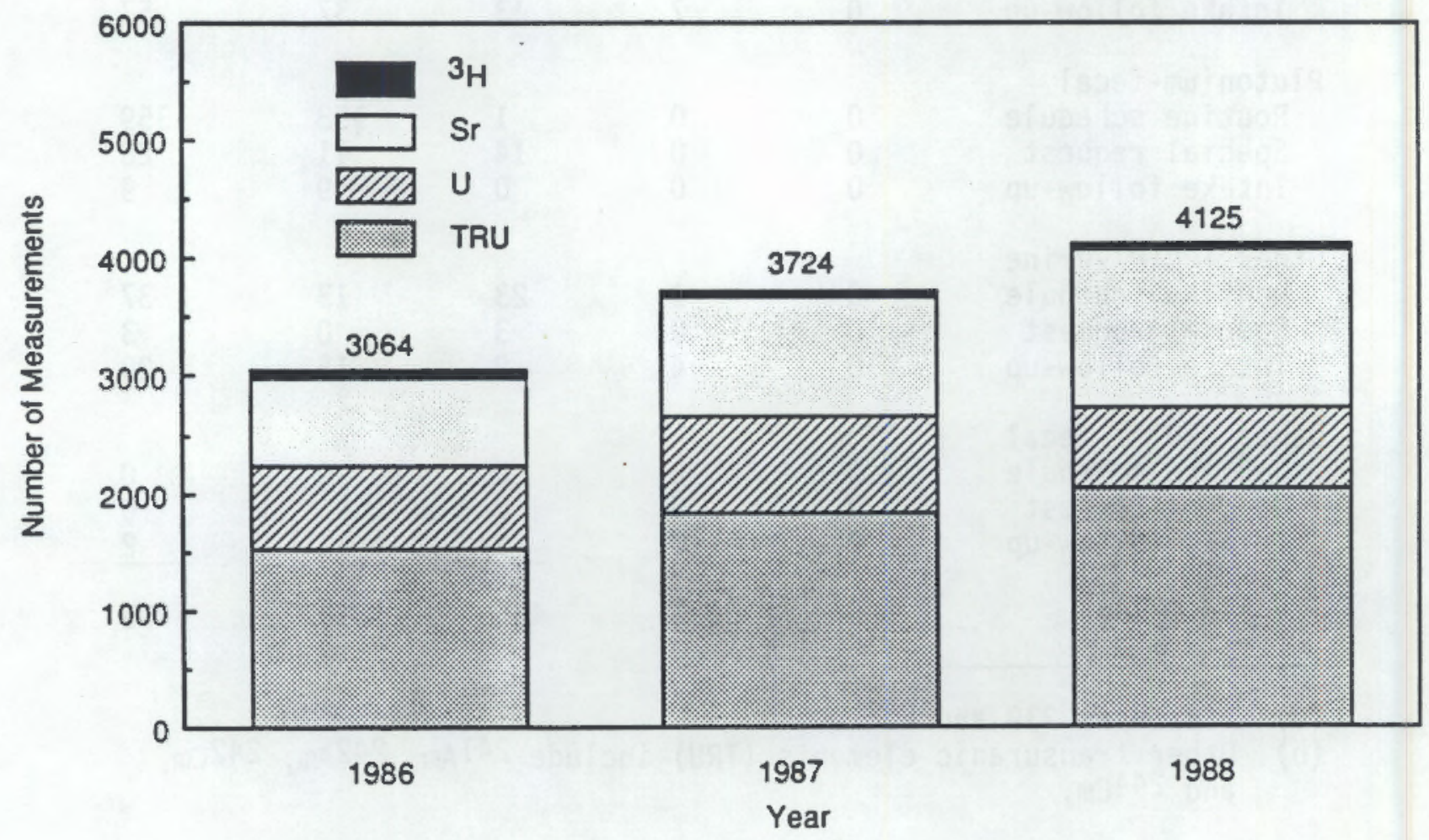

FIGURE 2. Routine Urine Measurements Recorded from 1986 Through 1988 


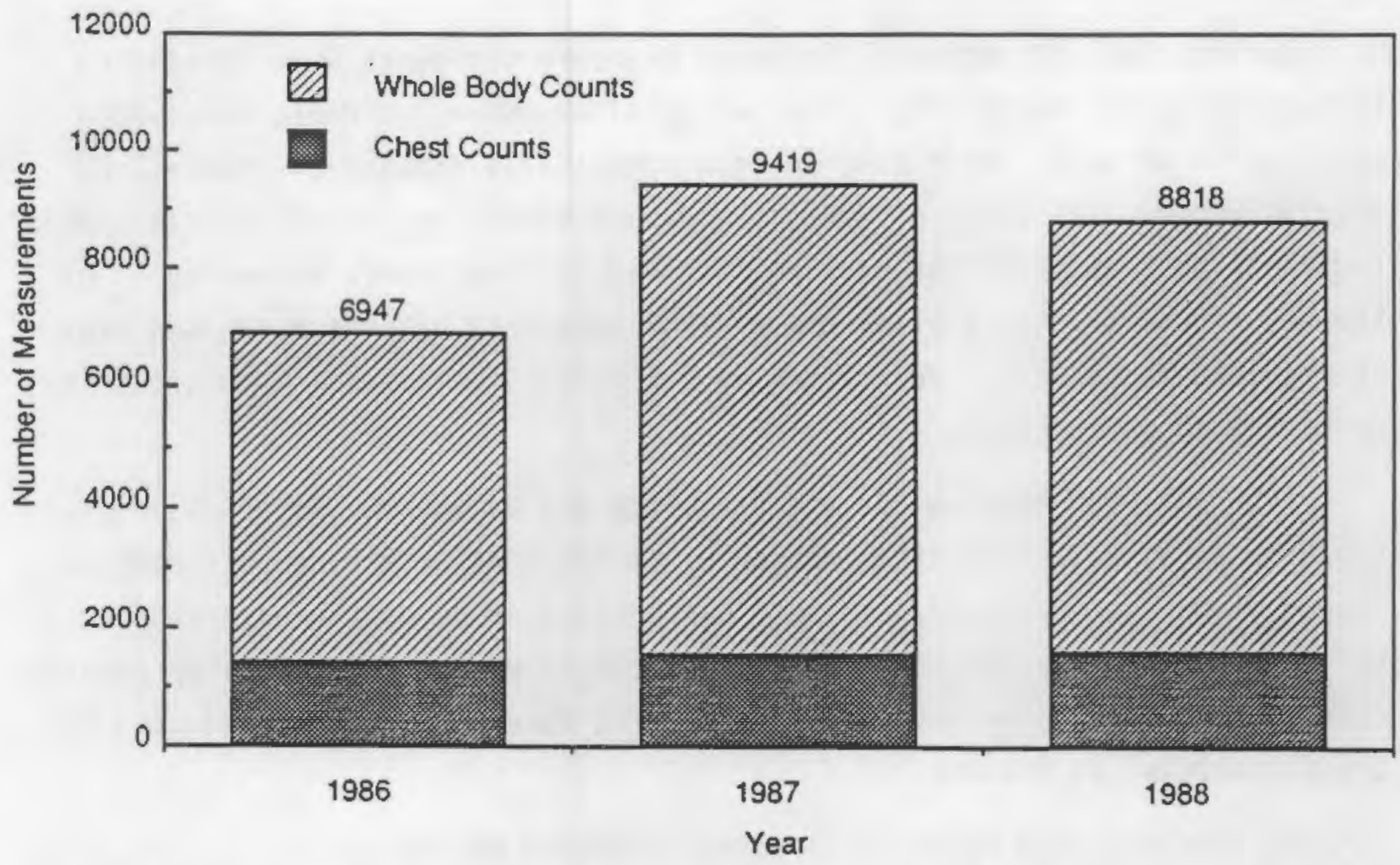

FIGURE 3. Routine In Vivo Measurements Recorded from 1986 Through 1988

the numbers of routine urinalysis and in vivo measurements performed from 1986 through 1988.

Investigations of possible internal exposure to radionuclides are performed following an indication of a possible intake that could result in an internal dose exceeding the investigation level of $1 \%$ of a DOE RPS or $1 \%$ of a maximum permissible body burden (MPBB). Cases that required investigation were identified by one of the following:

- workplace surveillance (eg., air sampling, contamination survey, contaminated wound)

- routine bioassay measurements

- other radiation protection considerations.

of the 13,302 routine bioassay measurements performed in 1988, 27 indicated possible occupational exposure greater than $1 \%$ of the DOE standard, and follow-up investigations were performed. However, none of the workers were determined to have incurred an internal dose in excess of $1 \%$ of the DOE standards. 
During 1988, 12 potential internal exposure incidents were identified through workplace monitoring. The potential exposure incidents involved a total of 25 workers. Of these, 14 were potentially exposed to short-lived fission and/or activation products, 3 to radiostrontium, and 8 to transuranic radionuclides. None of the workers received internal doses exceeding $1 \%$ of the DOE annual limit. A breakdown of 1988 incidents by contractor and area is provided in Table 6 . Annual trends for potential internal exposure incidents are shown in Figure 4.

Internal dose assessments are performed and documented after an investigation of potential internal exposure. Assessments are also performed to update or revise previously assessed doses based on current bioassay data. During 1988, eight assessments were conducted to update previously documented cases based on new bioassay data. Another 72 assessments were conducted and are categorized as follows:

- 26 resulted from potential internal exposure incidents

- 8 were performed at the special request of site contractors

- 38 were initiated as a result of a routine bioassay measurement. of these 72 assessments, in 22 it was concluded that no intake had occurred; in 42 it was concluded that an internal dose of less than $1 \%$ of the annual dose limit had occurred; and in 8 it was concluded that an annual dose of greater than $1 \%$ of the 1 imit had occurred. Of the eight cases exceeding $1 \%$, four exceeded $10 \%$ of the annual limit and one was projected to exceed $50 \%$ of

TABLE 6. Summary of Potential Exposure Incidents During 1988

\begin{tabular}{|c|c|c|c|c|c|}
\hline Area & $\overline{D O E}$ & $\begin{array}{c}\text { ber of } \\
\text { KEH } \\
\end{array}$ & $\begin{array}{c}\text { nts (ir } \\
\text { PNL }\end{array}$ & $\frac{\text { uals i }}{\text { WHC }}$ & 1) \\
\hline $100 \mathrm{~N}$ & 0 & 1 (11) & 0 & 0 & 1 (11) \\
\hline $200 \mathrm{~N}$ & 0 & 0 & 0 & 1 (1) & 1 (1) \\
\hline $200 \mathrm{~W}$ & 0 & 0 & 0 & $5(7)$ & $5(7)$ \\
\hline 300 & 0 & $2(3)$ & 3 (3) & 0 & $5(6)$ \\
\hline 400 & 0 & $\underline{0}$ & $\underline{0}$ & $\underline{0}$ & 0 \\
\hline Total & 0 & $3(14)$ & $3(3)$ & $\overline{6(8)}$ & $12(25)$ \\
\hline
\end{tabular}




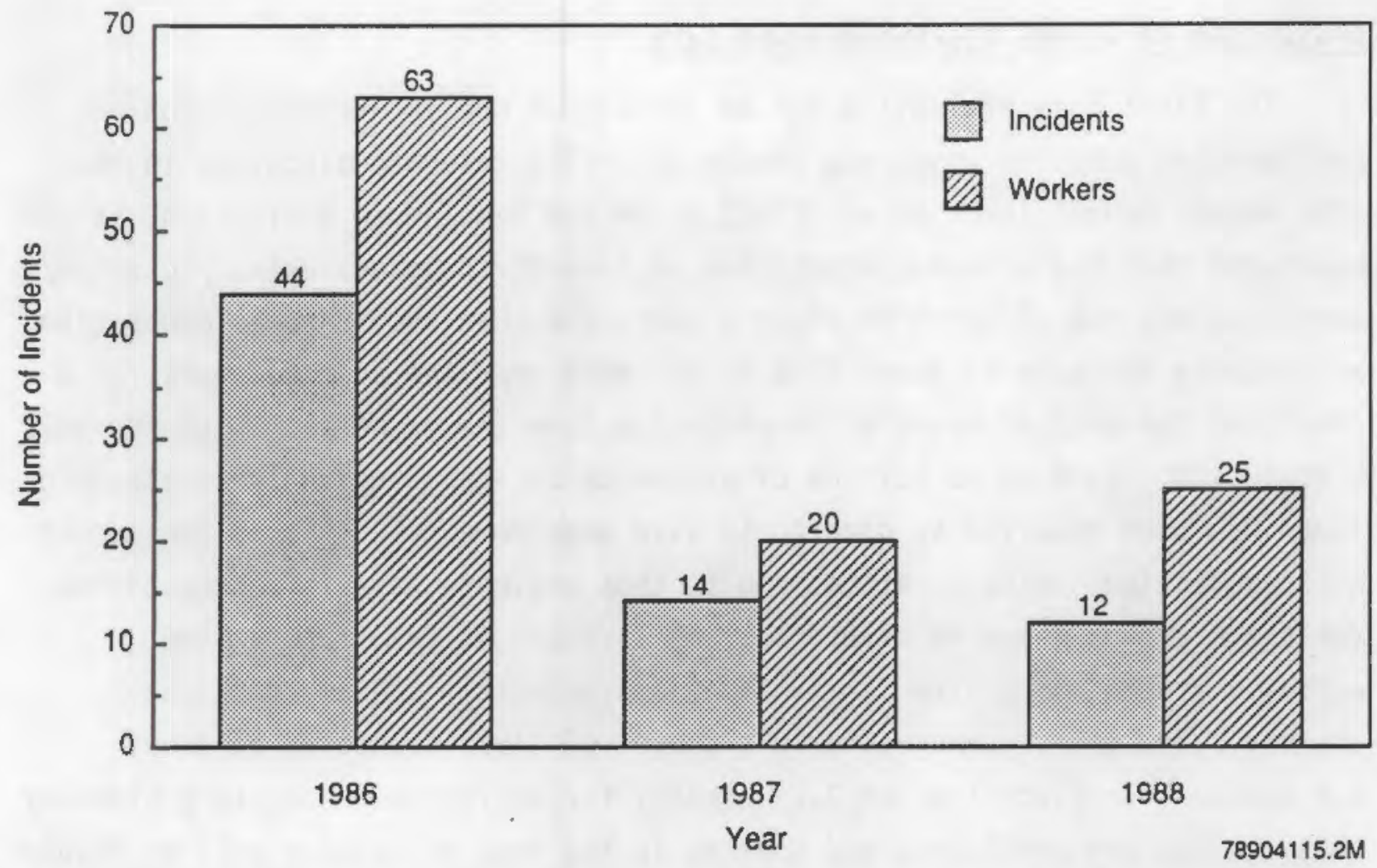

FIGURE 4. Summary of Contractor-Reported Incidents from 1986 Through 1988

the annual limit. This case involved a plutonium-contaminated wound in 1985, and is discussed in more detail in the next subsection.

The internal deposition status of the Hanford workforce at the end of 1988 is summarized in Table 7. All past exposures received by current workers are considered. The number of cases decreased from 98 in 1987 to 72 in 1988, largely due to worker retirements.

TABLE 7. Internal Dose Status of Hanford Horkforce at 1988 Yearend

Percent of

RPS or MPBB

$\geq 1-<5$

$\geq 5-<50$

$\geq 50$ - $<100$

$>100$

Total

\begin{tabular}{c|rrrr}
\multicolumn{5}{c}{ Number of Workers } \\
\hline$\overline{D O E}$ & $\frac{\text { KEH }}{2}$ & $\frac{\text { PNL }}{17}$ & $\frac{\text { HHC }}{24}$ & $\frac{\text { Total }}{44}$ \\
1 & 2 & 17 & 24 & 48 \\
0 & 1 & 7 & 18 & 26 \\
0 & 0 & 0 & 0 & 0 \\
1 & 0 & $\frac{0}{24}$ & $\frac{1}{43}$ & $\frac{2}{72}$
\end{tabular}




\section{Evaluation of a 1985 Plutonium Wound Case}

The final dose evaluation for an individual who incurred a plutoniumcontaminated puncture wound was completed. (The case was discussed in the 1987 annual report [Lyon et al. 1988].) In the final dose evaluation, it was concluded that the systemic deposition of long-lived bone-seeking plutonium/ americium was $40 \%$ of the MPBB after 1 year, and that the systemic deposition will slowly increase to about $120 \%$ of the MPBB over the next 50 years, as a result of the gradual transfer of plutonium from the wound site into systemic circulation. To date no buildup of plutonium or americium in the skeleton or liver has been observed by direct, in vivo measurements. This is consistent with projections based on urine samples that estimate deposition quantities for these organs below in vivo detection levels. At the present time, activity at the wound site is stable at approximately $130 \mathrm{nCi}$ of alpha activity, and urinary excretion levels are relatively constant at about $0.8 \mathrm{dpm} / \mathrm{day}$ for plutonium and $0.04 \mathrm{dpm} / \mathrm{day}$ for americium. Long-term bioassay measurements are continuing and updates to the dose evaluation will be issued periodically.

\section{BIOASSAY ANALYTICAL SERVICES}

Bioassay analytical services include excreta sample analysis provided by UST through a subcontract managed by PNL and by in vivo measurements performed by PNL. The following subsection discusses bioassay analytical services provided by UST. The in vivo measurement services provided by PNL in 1988 are reviewed in a separate section of this annual report.

Laboratory Operational Requirements

The Statement of Work(a) (SOW) for the fifth operational year of the contract with UST remained in effect throughout $\mathrm{CY} 1988$. Changes to the SOW for the fifth operational year were discussed in last year's annual report.

(a) "Statement of Work for the Fifth Operational Year of Subcontract B-B2472-A-I" (1987). Copy in the Hanford Radiation Protection Historical Files, Pacific Northwest Laboratory, Richland, Washington. 
During 1988, a new contract was negotiated and a new SOW(a) was developed to take effect on January 1, 1989. The principal change in the new SOW is a requirement to subtract the reagent blank value from gross sample results to produce net sample results. This procedure was actually implemented for samples received by UST beginning September 30, 1988.

\section{Laboratory Quality Control}

The internal quality control (OC) program operated by UST provides for monitoring and documentation of laboratory performance. The results of internal $O C$ samples are issued in an annual letter report.(b) The report covering QC samples analyzed during fiscal year (FY) 1988 showed performance to be satisfactory with respect to contractual requirements except for the following:

- The MDAs for routine and priority $90 \mathrm{Sr}$ analyses, either singly or in sequential analyses, were greater than the contractual detection level. In addition, low chemical yields and bias outside of the allowed uncertainty were obtained for some types of strontium analysis. This problem had carried over from previous years. United States Testing Company, Inc., conducted a thorough investigation of the procedure and reagents and developed a revised procedure. The revised procedure was in the review and signoff stage at year's end, and was targeted for implementation in January, 1989.

- Low chemical yields and bias outside the allowed uncertainty were also obtained for some types of americium/curium analysis. The americium/curium procedure was also revised in FY 1988, and the revised procedure was in the review and signoff stage at year's end, and was targeted for implementation in January, 1989.

In addition to the $Q C$ program operated internally by UST, the Hanford Internal Dosimetry Program submits samples containing known quantities of radionuclides in urine. The samples are submitted blind; that is, they are made to appear to be normal urine samples from Hanford workers. This

(a) "Statement of Work for the First Operational Year of Subcontract 005145A-M1" (1989). Copy in the Hanford Radiation Protection Historical Files, Pacific Northwest Laboratory, Richland, Washington.

(b) Bruce, P. 1988. Bioassay Annual Quality Control Report for Fiscal Year 1988. Letter report to Oon Bihl, dated November 14, 1988. United States Testing Company, Inc., Richland, Washington. Copy in the Hanford Radiation Protection Historical Files, Pacific Northwest Laboratory, Richland, Washington. 
external audit sample program provides a check on UST's own internal QC program. Analyses for tritium, $90 \mathrm{Sr}, 238 \mathrm{Pu}, 239 \mathrm{Pu}, 241 \mathrm{Am}$, and elemental uranium via two different methods were tested during FY 1988 and the results are documented in an annual report.(a)

The results of the external audit program were generally the same as for UST's internal QC program. Problems in UST's performance in analyzing for $90 \mathrm{Sr}$ and $241 \mathrm{Am}$ were noted and corrective actions were taken by UST as discussed above.

\section{SUPPORTING INVESTIGATIONS AND STUDIES}

Supporting work conducted during 1988 included the continuation of efforts to implement DOE 5480.11 (DOE 1989), an evaluation of bioassay methods for highly insoluble forms of plutonium, operation of a pilot routine fecal-sampling program, and an evaluation of plutonium deposition assessment methods.

Upgrades Supporting the Implementation of DOE 5480.11

DOE 5480.11, Radiation Protection for Occupational Workers (DOE 1989), was issued for compliance beginning January 1, 1989. Several tasks, aimed at preparing for implementation of the new Order, were completed during 1988:

- completion of the evaluation of pre-existing internal deposition cases in terms of annual organ and effective dose equivalent

- preparation of summary internal dose reports for all active workers with evaluated internal dose for use by contractor radiation protection organizations

- projection of CY 1989 internal doses due to past intakes for use by contractors to control the total effective dose equivalent during 1989.

(a) Bihl, D. E. 1989. Results of the Bioassay Audit Program for Fiscal Year 1988. Letter report, dated January 30, 1989. Copy in the Hanford Radiation Protection Historical Files, Pacific Northwest Laboratory, Richland, Washington. 
Evaluation of Methods to Improve Routine Bioassay Monitoring for Freshly Separated, Poorly Transported Plutonium

Several occupational exposure cases involving the inhalation of plutonium oxide at Hanford have shown clearance half-times from the lung that are much longer than the 500-day half-time recommended for class $Y$ plutonium in ICRP 30 (1979). This material is referred to as super class Y plutonium, and the ability to detect exposures to this material using current routine bioassay monitoring methods is relatively poor as shown in Table 8 . The urine sampling detection capabilities for super class $Y$ material are much less sensitive than for class $Y$ material. Therefore, potential improvements in bioassay methods for super class $Y$ plutonium were evaluated. The methods evaluated were lung counting, urine sampling, fecal sampling, and use of diethylene triamine penta acetate (DTPA) to enhance urinary excretion. Details of this evaluation are discussed by Bihl et al. (1988) and are briefly summarized below.

Lung counting could be enhanced somewhat by increasing counting times and by increasing the number of detectors. Routine chest counts are 15 minutes long and the sensitivity of the measurement could be increased by about a factor of 2 by increasing the counting time to 1 hour. Further increases in counting time would not be practical. An additional increase in sensitivity by a factor of 1.4 could be achieved by increasing the number of detectors in the chest-counting array from 6 to 12 at a cost of about $\$ 80 \mathrm{~K}$.

TABLE 8. Potentially Undetectable Doses from Intakes of Freshly Separated Weapons-Grade Plutonium Using Routine Bioassay Measurements

First-Year Effective Dose Equivalent, mrem

Class Y Super Class $Y$

Measurement First Year(a) Three Years First Year Three Years

$\begin{array}{lllll}\text { Chest counting } & 4700 & 3400 & 4400 & 2400\end{array}$

$\begin{array}{lllll}\text { Urine sampling } & 450 & 340(\text { b }) & 4700 & 2400\end{array}$

(a) First year means at 365 days after an intake and 3 years means at 1095 days post intake.

(b) The ability to detect a class $Y$ intake by urine sampling remains about the same between 1 to 3 years post intake. 
Urinalysis sensitivity could be improved by using mass spectrometry, fission-track analysis, or by upgrading current alpha-spectrometry methods. Fission-track analysis could potentially improve detection capability for super class $Y$ plutonium by about 2 orders of magnitude; however, fissiontrack analysis is currently only available at Brookhaven National Laboratory at about $\$ 1000 /$ analysis. However, Brookhaven cannot be considered to be a reliable long-term source for fission-track analyses because they are not geared for a production-type operation and could not handle the volume of samples that would be required. Implementation of fission-track analysis at Hanford would be expected to cost several million dollars. Mass spectrometry could potentially improve detection capability by a factor of 20 over current techniques. The capability could be established at Hanford for an initial cost of about $\$ 50 \mathrm{~K}$ and $\$ 1000 /$ sample. Improvements in alpha spectrometry could possibly yield a factor of 2 increase in sensitivity.

Fecal sampling offers a potentially high level of sensitivity using currently available analytical techniques, but its use suffers from interferences due to low levels of airborne contamination in facilities and from poor worker acceptance.

DTPA enhances urinary excretion of plutonium up to 100 times shortly. after its administration; however, its use in conjunction with routine bioassay monitoring would be fraught with legal and ethical considerations and is not recommended.

Bihl et al. (1988) recommended increasing chest-count times to 1 hour for at-risk workers and developing a more sensitive urinalysis for plutonium.

\section{Pilot Fecal-Sampling Program}

A pilot routine fecal-sampling program (discussed in last year's annual report. [Lyon et al. 1988]) was continued for approximately 100 workers on the Remote Mechanical C (RMC) line at the Plutonium Finishing Plant. Samples from nonexposed persons were also collected as control samples. Although the purpose of the sampling was to investigate an improved method for detecting acute intakes of nontransportable plutonium, the worker data, when compared with control sample data, also showed that a large portion of the worker samples $(40$ to $50 \%$ ) contained $239 \mathrm{pu}$ at statistically greater levels than the 
control samples. Special air samples collected by WHC confirmed the presence of low-level airborne plutonium concentrations sufficient to account for the activity observed in the fecal samples. This observation provided support for an improved air-sampling program in the 200 Area facilities.

Doses were calculated from the fecal sample data assuming chronic intake throughout 1988. A committed effective dose equivalent of $9 \mathrm{mrem}$ was calculated for RMC line workers for intakes incurred during 1988.

Comparison of Premortem and Postmortem Estimates of Plutonium Deposition

As a means of evaluating internal dose assessment techniques for plutonium, the estimates of internal deposition of plutonium based on bioassay data collected for occupational monitoring purposes were compared with postmortem estimates made by direct tissue analysis. This study was performed in cooperation with the United States Transuranium Registry (USTR) and involved evaluation of USTR file data for six former Hanford workers.

Estimates of skeleton and liver burden from the evaluation of the urinary excretion data were compared with estimates based on tissue samples collected posthumously from six former Hanford workers that had incurred internal depositions of plutonium during their employment at Hanford. Excretion data were evaluated using the Jones excretion function (Jones 1985) to describe the expected daily excretion of plutonium following uptake to blood, and using the Healy method (Healy 1957) to describe the transfer of plutonium from the initial site of deposition (wound site or lung) into the blood. All six cases involved exposure to a mixture of plutonium isotopes consisting mainly of $239 \mathrm{pu}$. Five of the six cases involved inhalation intakes and the other case involved a contaminated wound.

Table 9 lists the premortem and postmortem estimates for the six cases. The estimates are compared graphically in Figure 5. General consistency existed between the two methods; typically the premortem estimates of skeletal burden were higher than postmortem estimates, while the converse was true for the liver. As shown in Figure 5, the ratio of premortem-topostmortem estimates was 1.6 for skeleton and 0.3 for liver. The ratio of the premortem-to-postmortem estimate for the combined skeleton and liver was 0.76 . 
TABLE 9. Estimates of Plutonium in Skeleton and Liver, Bq

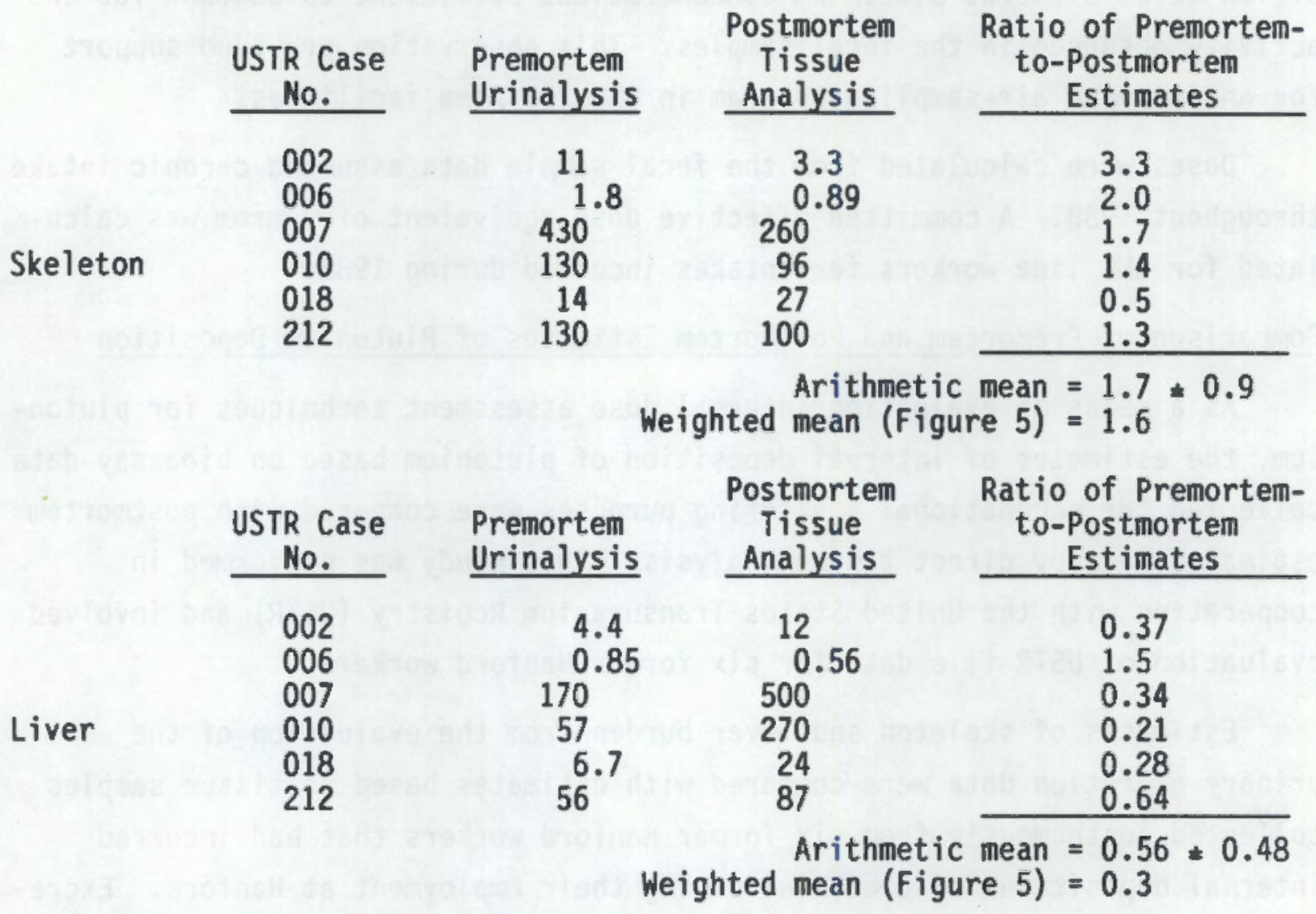

This work was presented at the Seventh Annual Congress of the International Radiation Protection Association in Sidney, Australia, in April, 1988, and was published in the proceedings (Australian Radiation Protection Society 1988).

\section{PRESENTATIONS}

Hanford Internal Dosimetry Program staff made the following presentations during 1988:

1. Bihl, D. E. 1988. "Human Data Supporting a Super Class Y Form of Plutonium." Paper presented at the Annual Health Physics Society Meeting, July 4-8, 1988, Boston, Massachusetts.

2. Bihl, D. E. 1988. "Problems with Detection of Intakes of Very Insoluble Plutonium." Paper presented at the 34th Annual Conference on Bioassay, Analytical, and Environmental Radiochemistry, October 17-21, 1988, Las Vegas, Nevada. 


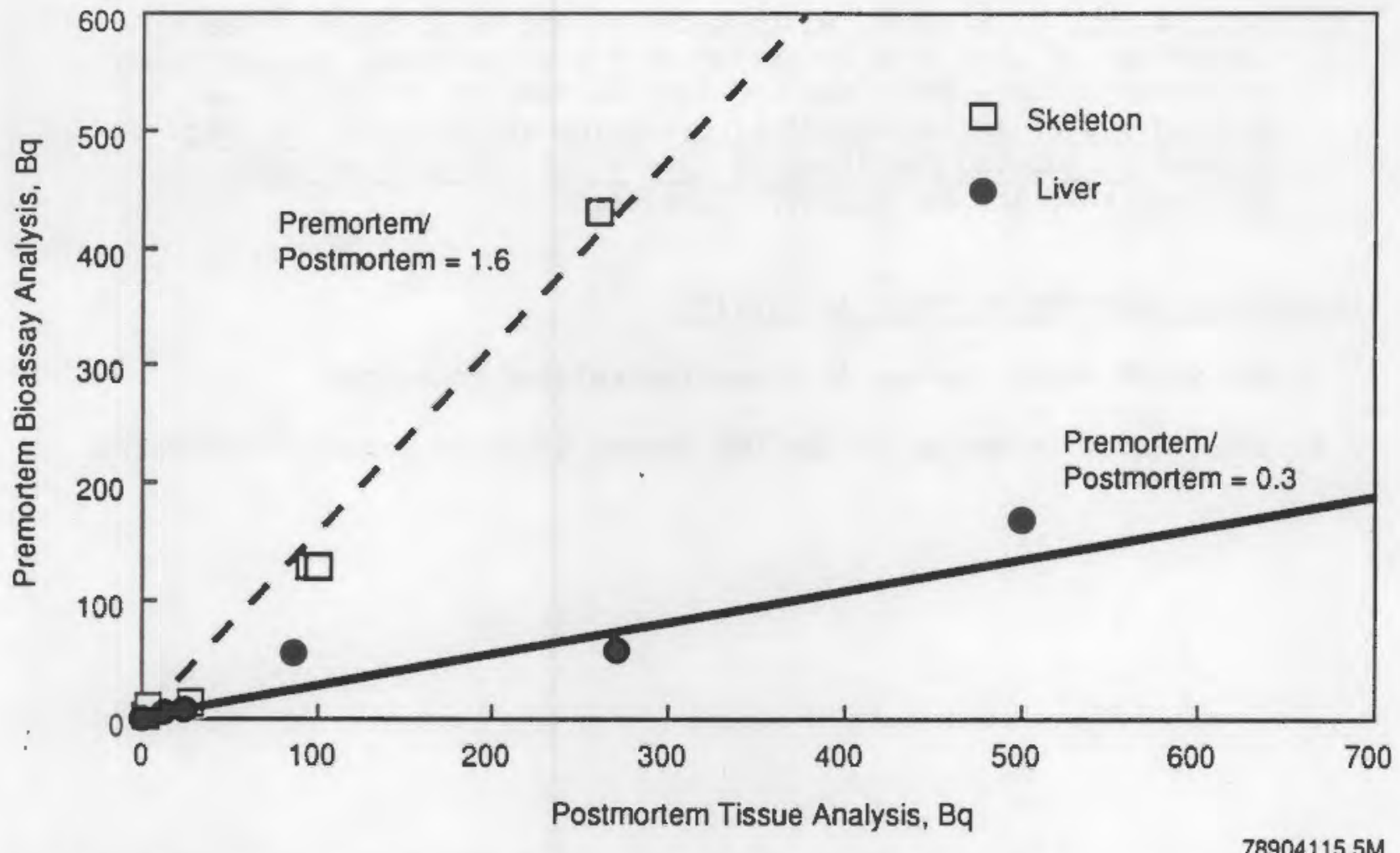

FIGURE 5. Comparison of Premortem and Postmortem Estimates of Plutonium in Skeleton and Liver

3. Sula, M. J., R. L. Kathren, D. E. Bihl, and E. H. Carbaugh. 1988. "Comparison of Premortem and Postmortem Estimates of Plutonium in the Skeleton and Liver of Six Individuals." Paper presented by R. L. Kathren at the 7th Congress of the International Radiation Protection Association, April 10-17, 1988, Sidney, Australia.

\section{PUBLICATIONS}

Program staff prepared or contributed to the following publications during 1988:

1. Bihl, D. E., T. P. Lynch, E. H. Carbaugh, and M. J. Sula. 1988. Methods to Improve Routine Bioassay Monitoring for Freshly Separated, Poorly Transported Plutonium. PNL-6695, Pacific Northwest Laboratory, Richland, Washington.

2. Carbaugh, E. H., M. J. Sula, T. L. Aldridge, and H. B. Spitz. 1988. "The Impact of Upgraded In Vivo Lung Measurement Capability on an Internal Dosimetry Program." In Proceedings of an International Symposium and Workshop on Lung Dosimetry, Inhaled Particles VI, The Annals of Occupational Hygiene, Vol. 32, pp. 885-892, Supplement 1 . 
3. Heid, K. R., J. J. Jech, R. L. Kathren, and M. J. Sula. 1988. "A Comparison of Long-Term Retention of Plutonium Oxide in Lung Based on Excretion Data With Observed Lung Burdens at Autopsy." In Proceedings of an International Symposium and Workshop on Lung Dosimetry, Inhaled Particles VI, The Annals of Occupational Hygiene, Vol. 32, pp. 901-907, Supplement 1.

\section{PROGRAM-RELATED PROFESSIONAL ACTIVITIES}

One staff member served on a program-related committee:

- Sula, M. J. -- Member of the DOE Expert Group on Internal Dosimetry. 


\section{HANFORD IN VIVO MEASUREMENT PROGRAM}

The In Vivo Measurement Program has been an integral part of personnel dosimetry at Hanford since 1959 to assist in detecting the deposition of radioactive materials in Hanford employees. Program requirements are outlined in the Hanford Site Services Handbook (DOE-RL 1983). The In Vivo Measurement Program provides for the management, operation, and maintenance of the in vivo counting facilities and equipment located in the 747-A Building, the 747-A Trailer, a mobile in vivo counting facility, and the Emergency Decontamination Facility. Operating hours are from 8:00 a.m. to 4:30 p.m. on weekdays. The facilities and equipment are also available during off-hours on an on-call basis, if needed. The results of measurements are transmitted electronically to the ORE database for permanent record. Daily operational and functional checks are performed on all routinely used counting systems, which are also periodically fully calibrated to ensure their accuracy. The staff participate in intercomparison programs to further improve the accuracy of operations. The activities of this program, including special studies and development work carried on during $\mathrm{CY}$ 1988, are described in the following subsections.

\section{ROUTINE PROGRAM}

Several types of routine in vivo measurements are made on personnel. The type of measurement made on employees is determined by the type of radioactivity to which they are potentially exposed. Generally, if an employee does not work with transuranic radionuclides, only a whole body count is performed to detect the higher-energy gamma rays from fission or activated corrosion products. If the work involves transuranic radio-nuclides, lung and whole body counts are done. If radioactivity is detected in either of these measurements, several other types of counts may be done to identify and quantify the activity in the body.

The number and types of measurements made on personnel during 1988 are shown in Table 10. During 1988, 8899 measurements were made for DOE and the Hanford contractors. This number is $9 \%$ less than the number for 1987. 
TABLE 10. Measurements Made on Personnel During 1988(a)

\begin{tabular}{|c|c|c|c|c|c|c|c|}
\hline Contractor & $\begin{array}{l}\text { Whole Body } \\
\text { Counts }\end{array}$ & $\begin{array}{c}\text { Lung } \\
\text { Counts } \\
\end{array}$ & Thyroid & Wound & Head & Other & Total \\
\hline DOE & 34 & 0 & 0 & 0 & 0 & 0 & 34 \\
\hline WHC & 4856 & 1229 & 0 & 3 & 34 & 10 & 6132 \\
\hline HEHF & 23 & 0 & 0 & 0 & 0 & 0 & 23 \\
\hline KEH & 1200 & 219 & 0 & 1 & 0 & 1 & 1421 \\
\hline PNL & $\underline{1074}$ & 204 & $\underline{2}$ & $\underline{1}$ & 7 & $\underline{1}$ & $\underline{1289}$ \\
\hline Total & 7187 & 1652 & 2 & 5 & 41 & 12 & 8899 \\
\hline
\end{tabular}

(a) Includes routine and special counts.

Figure 6 graphically depicts the in vivo measurements made at the Whole Body Counter (WBC) for the past 5 years. The 1988 total of 7247 whole body and other miscellaneous counts (other than lung counts) is $11 \%$ lower than the same total counted in 1987. Lung counts for 1988 totaled 1652 (3\% higher than in 1987).

ADDITIONS OR CHANGES TO EQUIPMENT AND FACILITIES IN 1988

Continued efforts to upgrade the accuracy, sensitivity, and operational efficiency of the WBC operations resulted in the addition of two shielded rooms, a contract to provide a new mobile counter, the addition of largevolume germanium detector array, and the extension of the Hanford local area network to the WBC facilities.

Construction of Two New Shielded Rooms

Two shielded rooms were added to the WBC facilities. One of the rooms was moved from the University of Utah where it had been used for about 25 years in a DOE-funded radiobiology study. This room has iron walls 12 in. thick and inside dimensions of $8 \mathrm{ft} \times 12 \mathrm{ft}$. The iron was constructed of armor plate from a World War II battleship. The room also has a graded shield of lead, cadmium, and copper to reduce the background at low energies. 


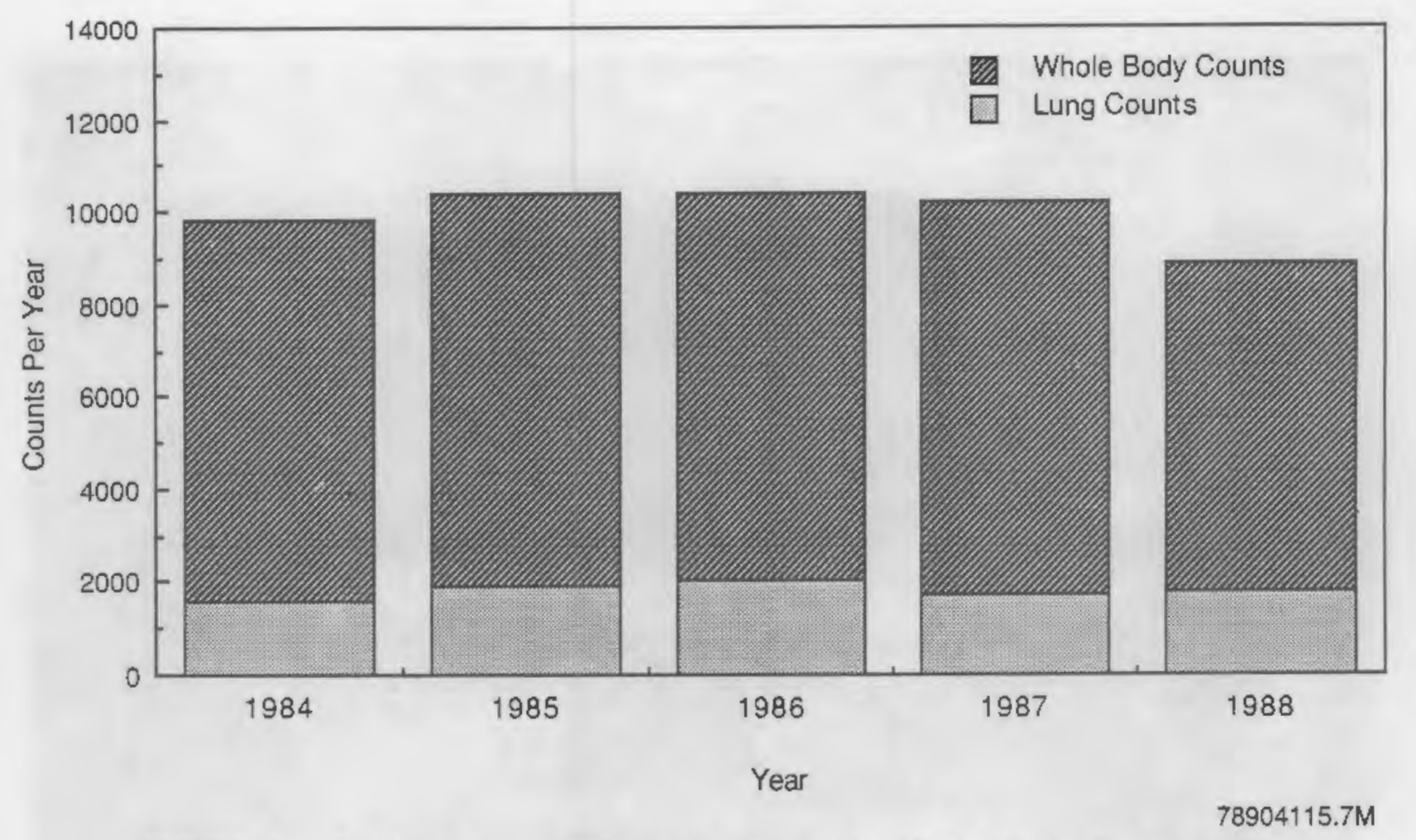

FIGURE 6. In Vivo Measurements Made at the Whole Body Counter, 1984 Through 1988

Photographs of the footing and the assembly of the walls of this room are shown in Figures 7 and 8, respectively. The "Utah" room was installed $9.5 \mathrm{ft}$ from the previously existing iron room, which provided two sides for another shielded room. The other two sides were added using 7-1/2 in. of battleship armor plate, and the ceiling and floor of the "middle" room were added using 5 in. of armor plate plus 4 in. of lead. The armor plate for this middle room was procured several years ago from the Nevada Test Site in anticipation of constructing additional shielded rooms. The middle room will have a graded shield of lead, tin, and stainless steel. The tin is used instead of cadmium because it presently costs less, and the stainless steel is used instead of copper because it does not tarnish and scratch as easily, but still provides sufficient absorption of the tin $x$ rays. A preliminary measurement of the background in the two new rooms showed the background to be as low as or lower than the older iron room. 


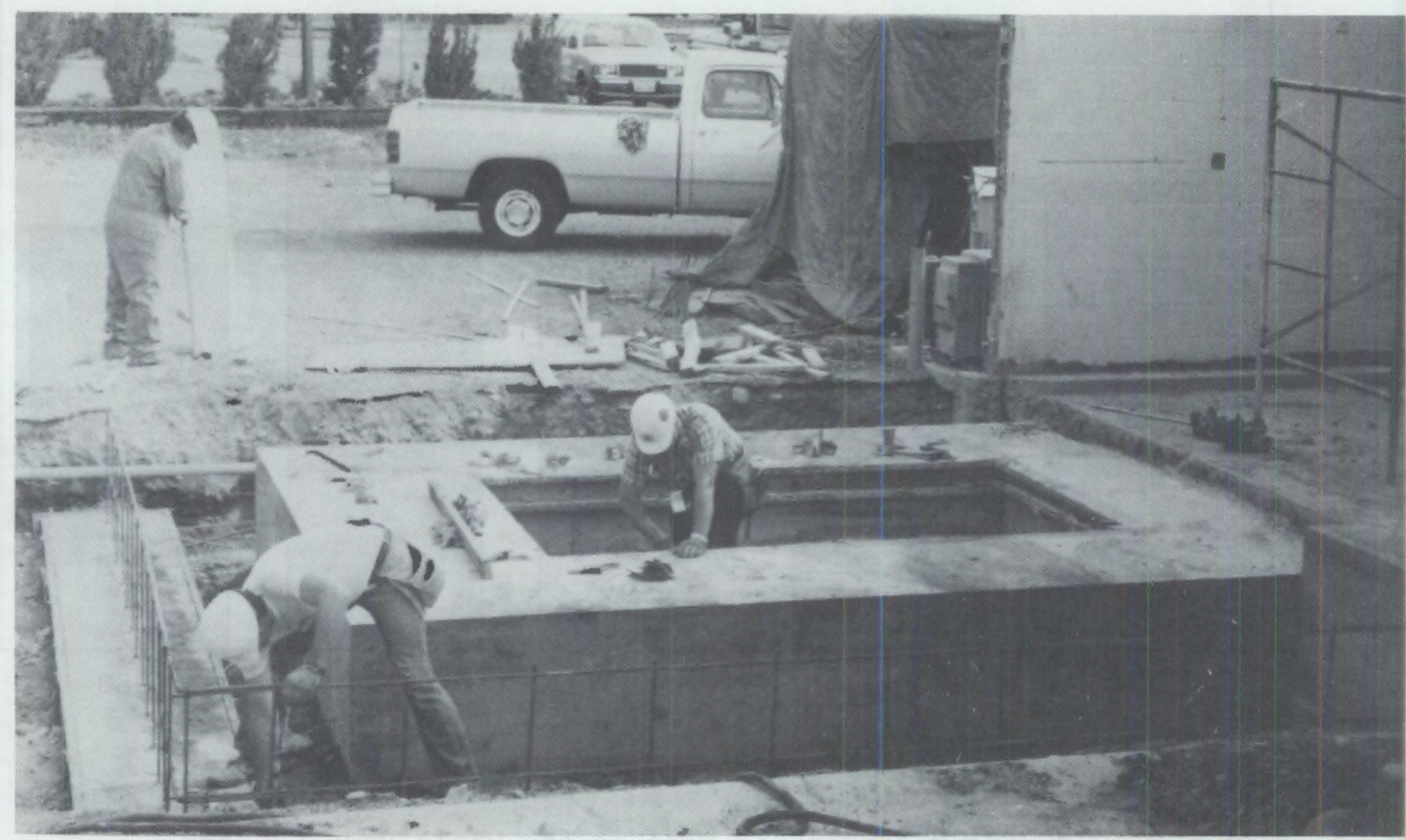

FIGURE 7. The Construction of the Footing for the Shielded Room Moved from the University of Utah

As of the end of 1988 the new rooms were not available for use because construction on the middle room was in the final stages, which includes the installation of the graded shield and the door-moving mechanism. The middle room will be used for a second lung-counting system and the Utah room will have multiple uses, but its primary use will be to quantify all positive burdens of radioactivity that emit gamma rays above $200 \mathrm{keV}$. This will be done using the new array of three large-volume germanium detectors that are described in the next subsection. 


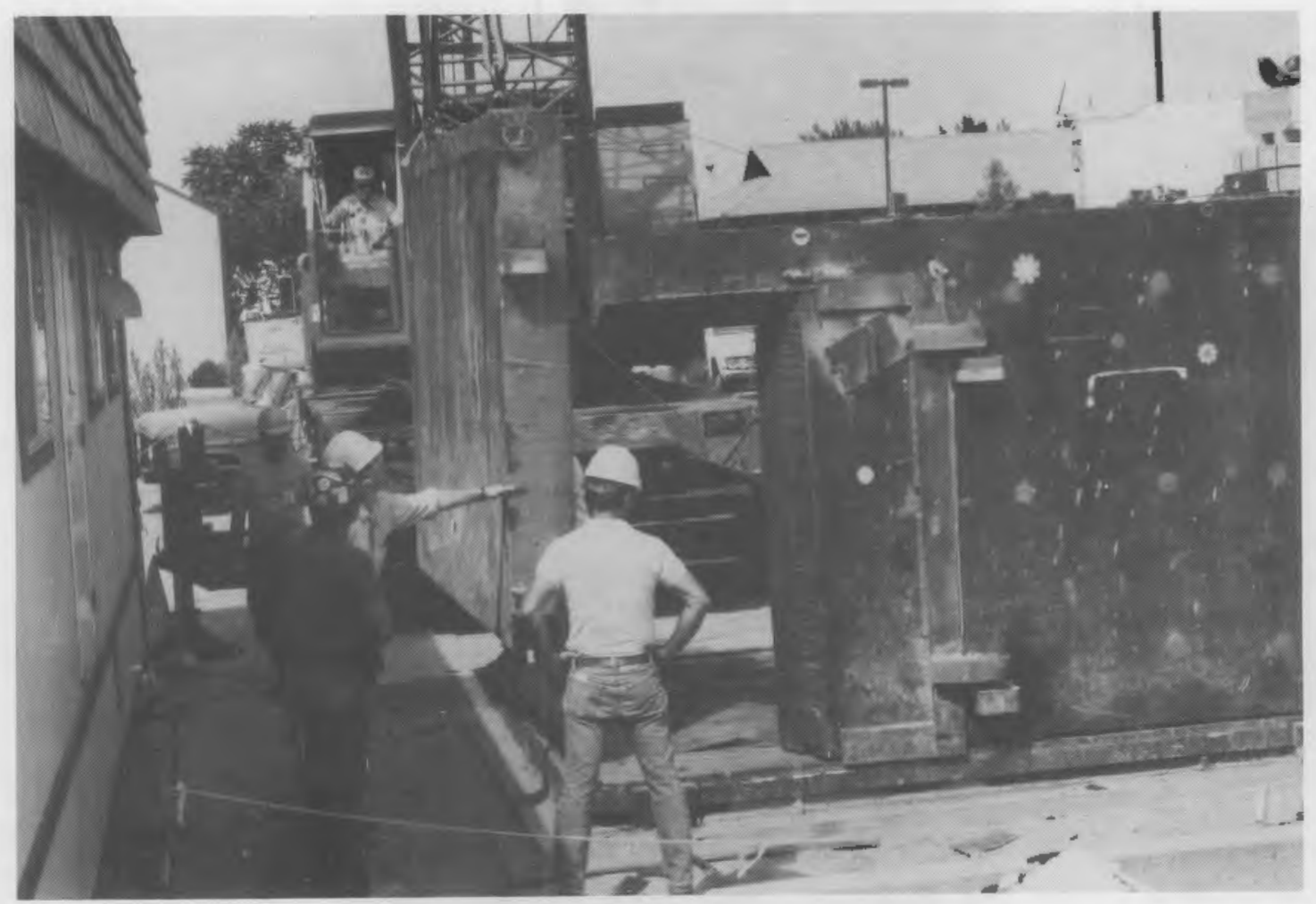

FIGURE 8. The Assembly of the Walls of the Utah Shielded Room

\section{Array of Large-Volume Germanium Detectors}

Two more large-volume germanium detectors were procured during the year. The counting efficiencies, as compared with a 3-x-3-in. NaI(T1) detector, are $66 \%$ for one and $69 \%$ for the other. When added to the $59 \%$-efficient detector procured in 1987, the total efficiency for the three detectors is $194 \%$ or essentially the same as two 3-x-3-in. NaI(TI) detectors. Figure 9 is a photograph of an array of three germanium detectors as it will be used for whole body and partial body measurements in the recently completed Utah room. The sensitivity of this germanium array for higher-energy gamma rays in the body and for a single radionuclide now exceeds the sensitivity of the fivedetector array of large-area $\mathrm{NaI}(\mathrm{Tl})$ detectors, and this germanium array is much more sensitive and accurate for quantifying mixtures of radionuclides in 


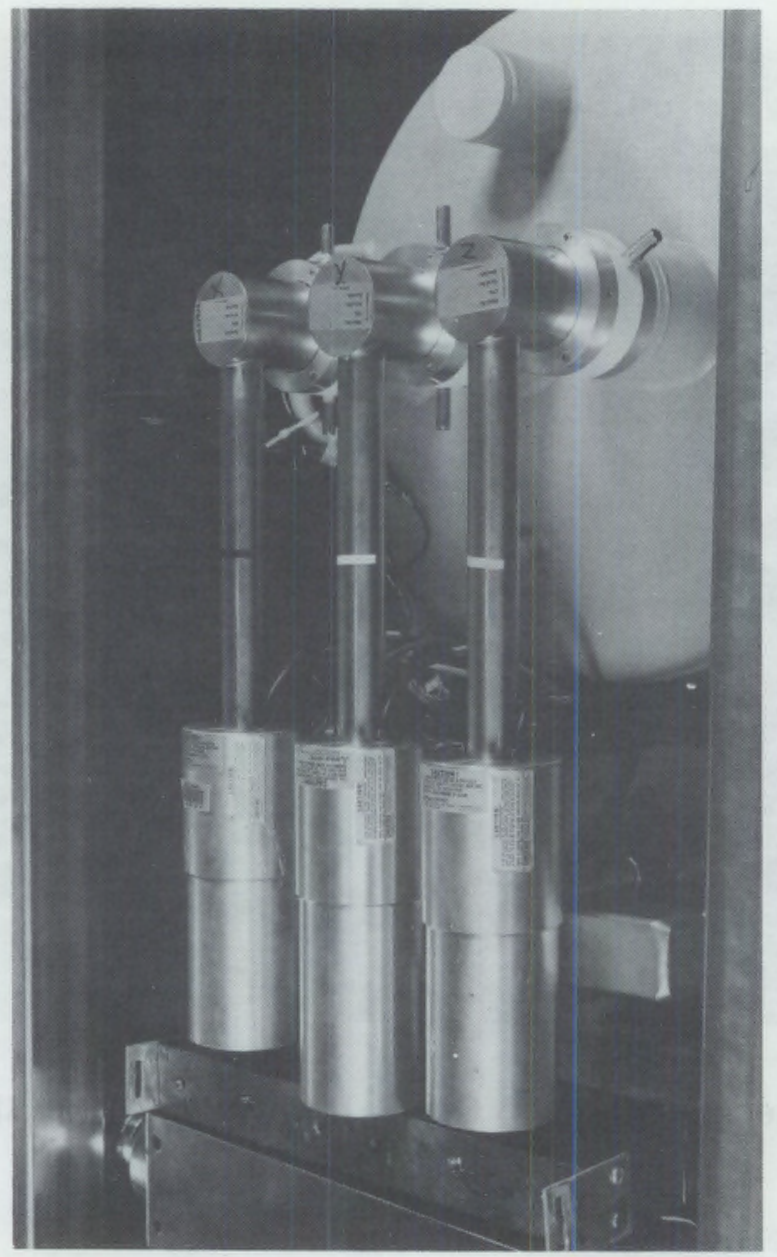

FIGURE 9. The Three-Detector Array for Whole and Partial Body Measurements in the Utah Shielded Room

the body. As an example of the sensitivity, the $24 \mathrm{Na}$ produced in the body (about $0.05 \mathrm{nCi}$ ) during long commercial airline flights can be detected with this array.

This array of germanium detectors will be used to quantify all positive body burdens of radionuclides except for naturally occurring $40 \mathrm{~K}$ and lung and skeleton burdens of low-energy $x$ - and gamma-ray emitters. All workers who show internally deposited radioactivity when measured on the preview counter will be subsequently measured with this large-volume germanium array, and these measurements will provide the basis for reporting the quantity of detectable radioactivity. 


\section{New Support System for Planar Germanium Detectors}

During the past several years, the support system used for the germanium planar detectors (used for lung, head, and liver counting) has not had the flexibility that is often needed to easily place the detectors over the proper location of the body for different-sized and -shaped bodies and for different locations on the body. Better methods of suspension have been considered for the past few years. Several flexible-arm systems for holding dental x-ray units were considered, but were not satisfactory for multipledetector systems. After several options were considered, a heavy-duty arm system manufactured by Dectron Products of Newberg, Oregon, was combined with a positioning device manufactured by King Tool Inc. of Bozeman, Montana. This combination provides the strength, all the positioning degrees of freedom, and position-maintenance requirements for in vivo measurements. The positioning device required extensive modification to make it serviceable for use with in vivo counting. The detector holders are shown in Figure 10 and the supported detectors on a subject are shown in Figure 11. This system has been used in the lead room for the past several months for head counting and special lung counts. The system will be used in the new middle room for supporting the second lung counter as soon as the room construction is complete.

New Mobile Whole Body Counter

A contract to provide a new mobile whole body counter van was awarded by WHC to a local construction company. The new mobile counter will include a shadow-shield WBC and a shadow-shielded area where thyroid, head, and other special measurements can be performed. The shadow-shield counter will be transferred from the old mobile unit to the new one.

\section{SPECIAL STUDIES CONDUCTED IN 1988}

One of the objectives of the In Vivo Measurement Program is to maintain state-of-the-art methods and instrumentation for in vivo measurements. This is accomplished by conducting special studies directed toward obtaining improved accuracy and sensitivity for in vivo measurements. Other studies are conducted to improve the efficiency of the WBC operations. Some of the more important studies are described below. 


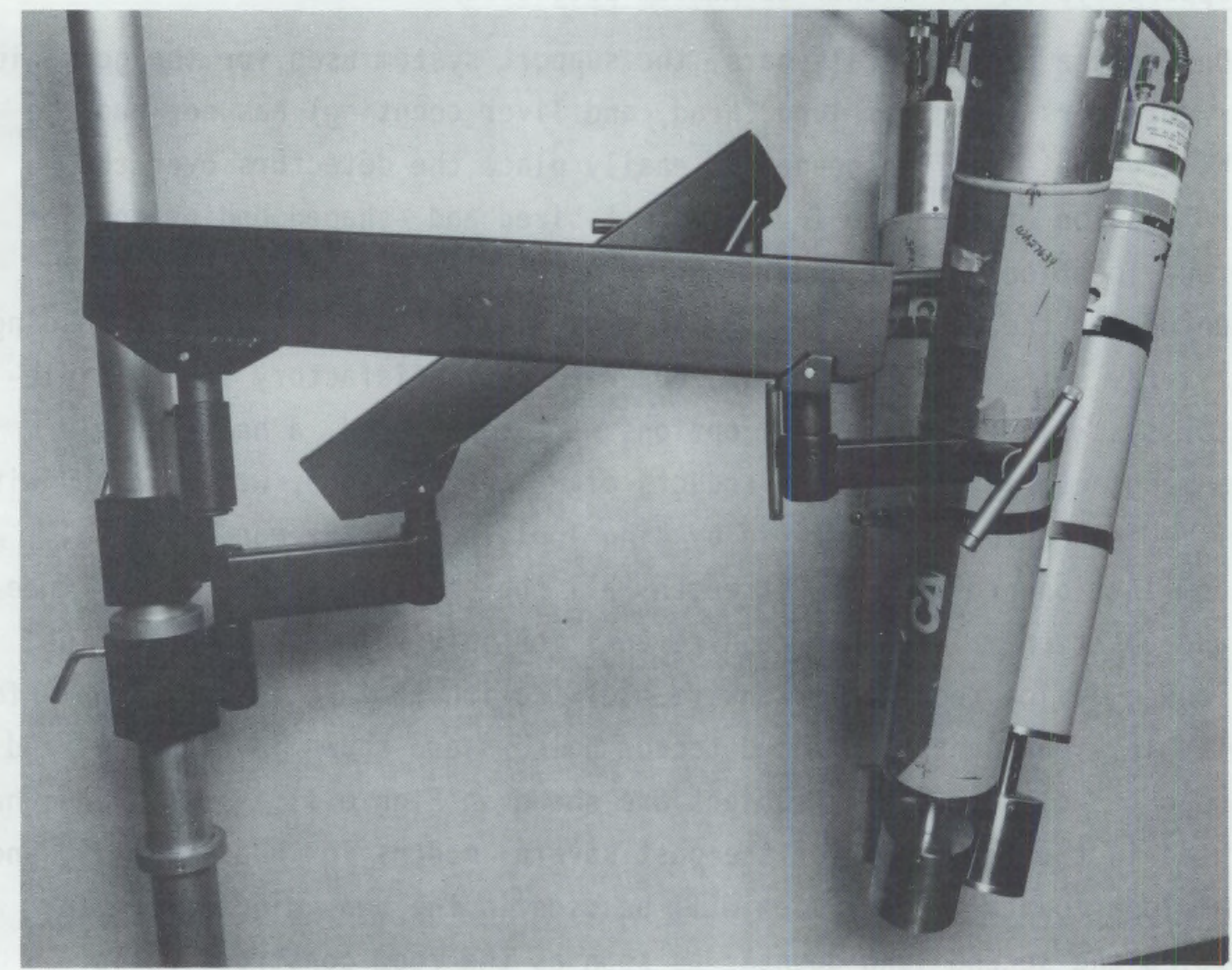

FIGURE 10. New Holders for the Planar Germanium Detectors

Calibration for Skeletal Content of Radionuclides by Measuring Subjects with Known Skeleton Contents of $133 \mathrm{Ba}$

A calibration curve for head counting was shown in the Hanford In Vivo Measurement Program report for 1987 (Lyon et al. 1988). The curve was derived from data obtained by conducting a head count on a person from England who had a known amount of ${ }^{133} \mathrm{Ba}$ in the skeleton. This calibration curve was in excellent agreement with a calibration curve obtained using the head phantom that had been constructed from the skull of a total body donation to the USTR, where the skeleton contained a known amount of $241_{\text {Am. }}$. Further measurements on the same subject and two other subjects having known amounts of $133 \mathrm{Ba}$ in the skeleton have shown that the original agreement with the 241 Am data was fortuitous. The first subject was later found to have a very abnormal asymmetrical distribution in the skull, and the detector 


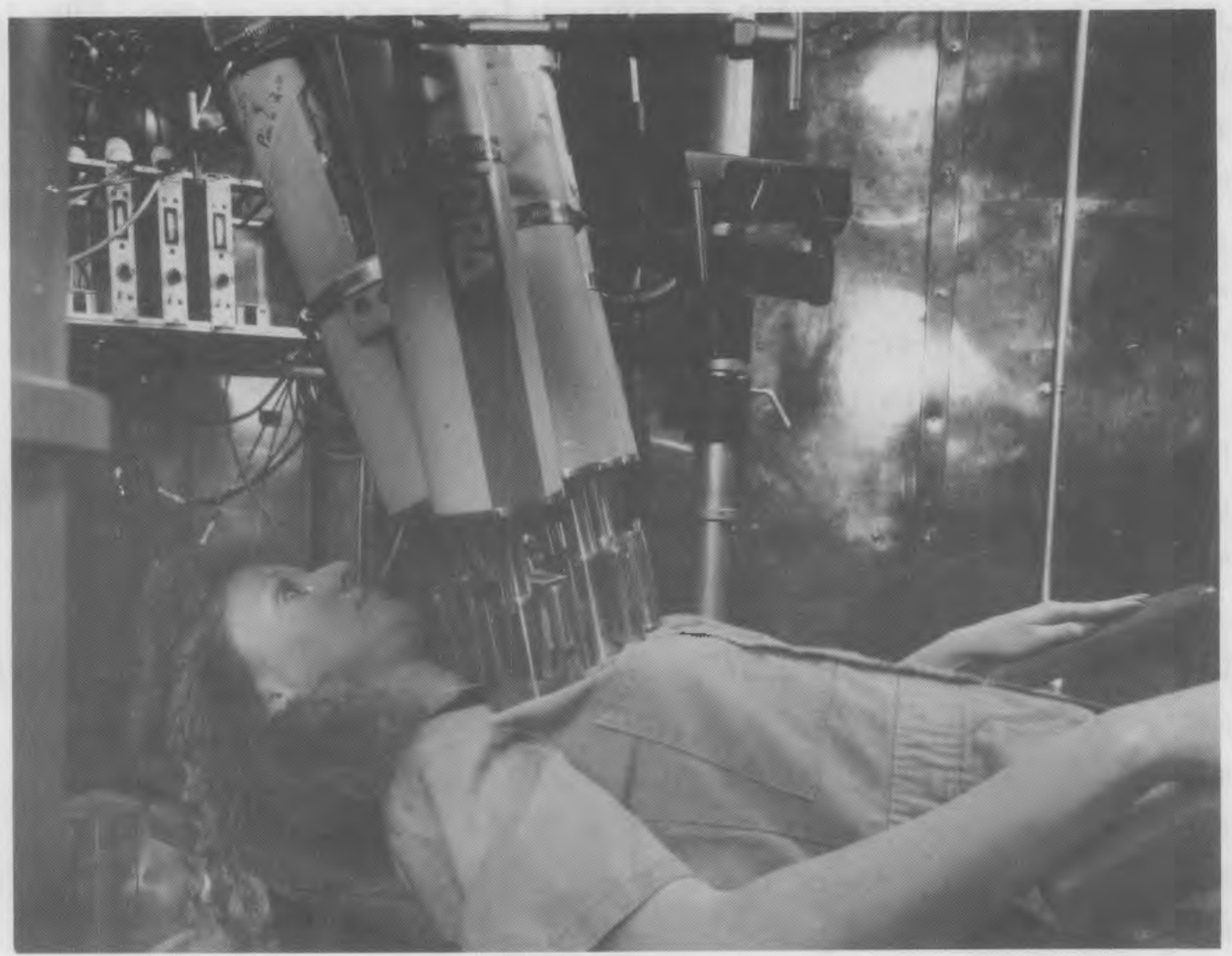

FIGURE 11. Supported Planar Germanium Detectors in Use on a Subject

responses for measuring the skull of the other two subjects were not in agreement with each other nor with the first subject. It appears that when ${ }^{133} \mathrm{Ba}$ is released from the skeleton, only a small percentage is reabsorbed into bone tissue. Thus after the initial deposition in the skeleton, the distribution in the bone changes with time because the trabecular bone releases the ${ }^{133} \mathrm{Ba}$ at a more rapid rate than the cortical bone. Because the three subjects were measured at significantly different times after intake of the $133 \mathrm{Ba}$, the ratio of the amount in the skull to that in the total body was different. Therefore, skeletal burdens of $133 \mathrm{Ba}$ cannot be used to calibrate the skull-counting method for determining the content of other radionuclides such as $241 \mathrm{Am}$ and $239 \mathrm{Pu}$ which, when released from the bone, are largely reabsorbed back into bone. 
Niobium-92m Studies for Improving Calibration Factors for Measuring 239pu in the Lung

Three male subjects from England, containing known quantities of $92 \mathrm{mnb}$ in the lung, were measured and studied during the year. Niobium-92m emits $x$ rays that have approximately the same energy as $x$ rays from $239 \mathrm{Pu}$. This was part of a new series of measurements where the subjects inhaled the $92 \mathrm{~m} \mathrm{Nb}$ attached to a particle size of $1 \mathrm{~mm}$. In a previous series of measurements conducted a few years ago, the subjects inhaled the $92 \mathrm{~m} N \mathrm{Nb}$ attached to 5- $\mu \mathrm{m}$ particles. Most of the subjects were the same people who participated in the study using the $5-\mu \mathrm{m}$ particle size. This current study will provide information on the effect of particle size on the distribution and counting efficiency of inhaled 239pu. Preliminary data indicate that the smaller particle size results in a $30 \%-$ to- $50 \%$ increase in counting efficiency, which, presumably, is due to a different distribution within the lung. These preliminary data agree with the results obtained by PNL several years ago when a Hanford employee inhaled some 238pu in the form of very small particles and the count rate over the lung was about two times that expected for the amount of activity in the lung.

Preliminary Results Given to Workers at the Completion of a Measurement

Starting in April, 1988, a form letter is now given to each DOE contractor employee at the end of his/her in vivo measurement. The letter, entitled "Preliminary Analysis of In Vivo Examination," was developed by the Internal Dosimetry Group and approved by the WBC staff and the DOE contractors. The computer-generated letter contains three standard descriptions of the results of in vivo measurements, and the appropriate description is marked by the WBC staff member who performed the measurement. Each employee receives such a letter when the count and analysis are complete. A copy of the letter is shown in Figure 12. It provides all the information that the employee needs concerning the results of the measurement, thereby eliminating the need for the employer to provide the information to the employee. 
NAME

PAYROLL

DATE

$07: 51$

Preliminary analysis of your in vivo examination(s) indicates:

Your in vivo measurements are completed, and the results do not exceed the criteria for followup.

Analysis of the examination data is not immediately available. The results of this examination will be provided to your company's radiation protection organization when available.

Your measurement exceeded a screening level.* A further review of the examination will be performed and your radiation protection organization will be notified of the results. Followup measurements may be required.

* The screening level is used to determine if there is a need for further evaluation of possible internal radioactivity

Please note: This report is based on a preliminary evaluation of your measurement by computer and is subject to change based upon additional review. If there is a change from the above reported results, Personnel Dosimetry will notify your company's radiation protection organization.

If you have any questions concerning your in vivo examiniaton please contact the following representative of your company's radiation protection organization:

Co. Name Phone

\section{FIGURE 12. "Preliminary Analysis of In Vivo Examination" Form Letter}

Feasibility of the Remote Operation of a Whole Body Counter

The need for WBC services at locations on the Hanford Site other than the 747-A Building has been considered several times in recent years. Strong consideration was given to building a WBC at $100-\mathrm{N}$ to provide more rapid and frequent monitoring of radiation workers for internal contamination to obtain more efficient use of radiation workers. This need no longer exists with 
the shutdown of $\mathrm{N}$ Reactor operations. The other location that has been considered is the HS-1 Building where approximately 6000 WBC measurements could be performed in conjunction with employee annual medical examinations that are performed by HEHF physicians. A 1983 study(a) of the costs of operating a facility at the HS-1 Building showed that with a full-time technician working at the WBC, the operations would not be as cost-effective as having the workers travel to the 747-A Building to receive $\mathrm{WBC}$ services.

The remote operation of WBCs has been considered in previous years, but the cost of transmitting and receiving video communication using microwave or satellite transmission has been prohibitive. Equipment is now available to transmit clear video images every 7 seconds over ordinary telephone lines, opining up the possibility of remotely operating a WBC at the HS-1 Building. No increase in WBC personnel would be required, and it appears that such a counter would be cost-effective and the initial cost could be compensated within a few years by the savings in worker time needed to travel to the 747-A Building.

For a feasibility study and test, the decision was made to use the preview counter in the 747-A Building, but have the operator located in the 747-A Trailer. The audio, visual, and data communication between the operator and the worker to be measured and between equipment would be via telephone lines. The operator would be able to see the workers, identify them by their security badges, note when they are in the proper counting position, carry on a conversation with them, and give them instructions. The workers could hear the operator and follow instructions, but it was not necessary for them to see the operator.

Video telephone equipment was loaned to PNL by Photophone Northwest for the feasibility study. The Photophone equipment can transmit both voice and high-resolution, black-and-white still pictures over regular telephone lines with no distance limitation or degradation of the picture. A still picture

(a) Palmer, H. E. 1983. Results of a Survey Among the Hanford Project DOE Contractor Employees on the Impact of the Separation of the Whole Body Counter and HEHF Medical Facilities. Copy in the Hanford Radiation Protection Historical Files, Pacific Northwest Laboratory, Richland, Washington. 
is transmitted every 7 seconds, but is not transmitted during voice communication. Although the Photophone equipment loaned to PNL only had one video camera, two cameras can be attached and the Photophone can be remotely switched from one camera to the other. The video camera did not have automatic focusing, so it was not possible to view the person's security badge, face, and position in the counter with the same camera. For the demonstration, a closed-circuit television system was used to observe the security badge; but if a remote counter were built, this system would be replaced by a second camera attached to the Photophone. A camera is not needed for the Photophone unit in the 747-A Trailer, because the person being counted does not need to see the operator.

Representatives from DOE-RL and all Hanford contractors were present to observe the actual measurement of several people in the preview counter, which was being operated remotely from an office in the 747-A Trailer. Some of the representatives and a few workers coming to the WBC for their annual count were measured. The people to be counted were told by a technician in the WBC where to go to receive their instructions, and the same technician also adjusted the height of the detector array once the person was in the counting position. The remainder of the count was conducted by the technician in the 747-A Trailer; when the counter was finished, the person was asked to pick up their measurement summary letters that had been generated (see Figure 12). The video and audio communication was satisfactory and valid counts were made in every case. The data transfer between the multichannel analyzers (MCAs) was somewhat slow, but this can be greatly improved by better software programing. The verbal response from the contractor representatives was that the remote operation of the WBC would meet their approval.

A remotely operated WBC in the HS-1 Building is not expected to require any operating personnel at the counter except for a daily energy and efficiency calibration that would be performed each morning and would take about 15 minutes. Once the person has been directed to the room where the counter is located, the written instructions in the room and verbal instructions from the technician in the 747-A Building should allow for the person to be measured in an accurate and safe manner. The WBC should be constructed 
so that the worker being counted could adjust the height of the detector array according to instructions given by the technician, who would be viewing the position on the Photophone.

Information on the count should be immediately available to the person who has been counted from a printer controlled by the MCA in the room because it is now at the 747-A Building. If any radioactivity were observed in the count other than natural $40 \mathrm{~K}$, the person would be directed to go to the $747-\mathrm{A}$ Building for further in vivo measurements.

Because the Photophone does not allow for simultaneous voice and video transmission, a third phone line may be needed; however, two dedicated phone lines should be adequate. The equipment schematic for a remotely operated WBC at the HS-1 Building is shown in Figure 13.

It is recommended that the remote $W B C$ be identical to the one at the 747-A Building so as to achieve identical calibration factors. The study and demonstration have shown that there are no major obstacles to overcome, and that a remotely operated WBC for measuring gamma rays emitted from the body is technically feasible.

\section{PUBLICATIONS}

Program staff contributed to the following publications during 1988:

1. Palmer, H. E., and M. C. Rhoads. 1989. "The Measurement of Pu-239 to $\mathrm{Am}-241$ Ratio in Wounds by Measuring the $\mathrm{L} \times$ rays with a $\mathrm{Si}(\mathrm{Li})$ Detector." Health Physics (in press)

2. Breitenstein, B. D., and H. E. Palmer. 1989. "Lifetime Followup of the 1976 Americium Accident Victim." Radiation Protection Dosimetry (in press)

3. Palmer, H. E., G. A. Rieksts, S. J. Jefferies, and K. J. Gunston. 1989. "Improved Counting Efficiencies for Measuring Pu-239 in the Lung in the Sitting Position." Health Physics (in press) 


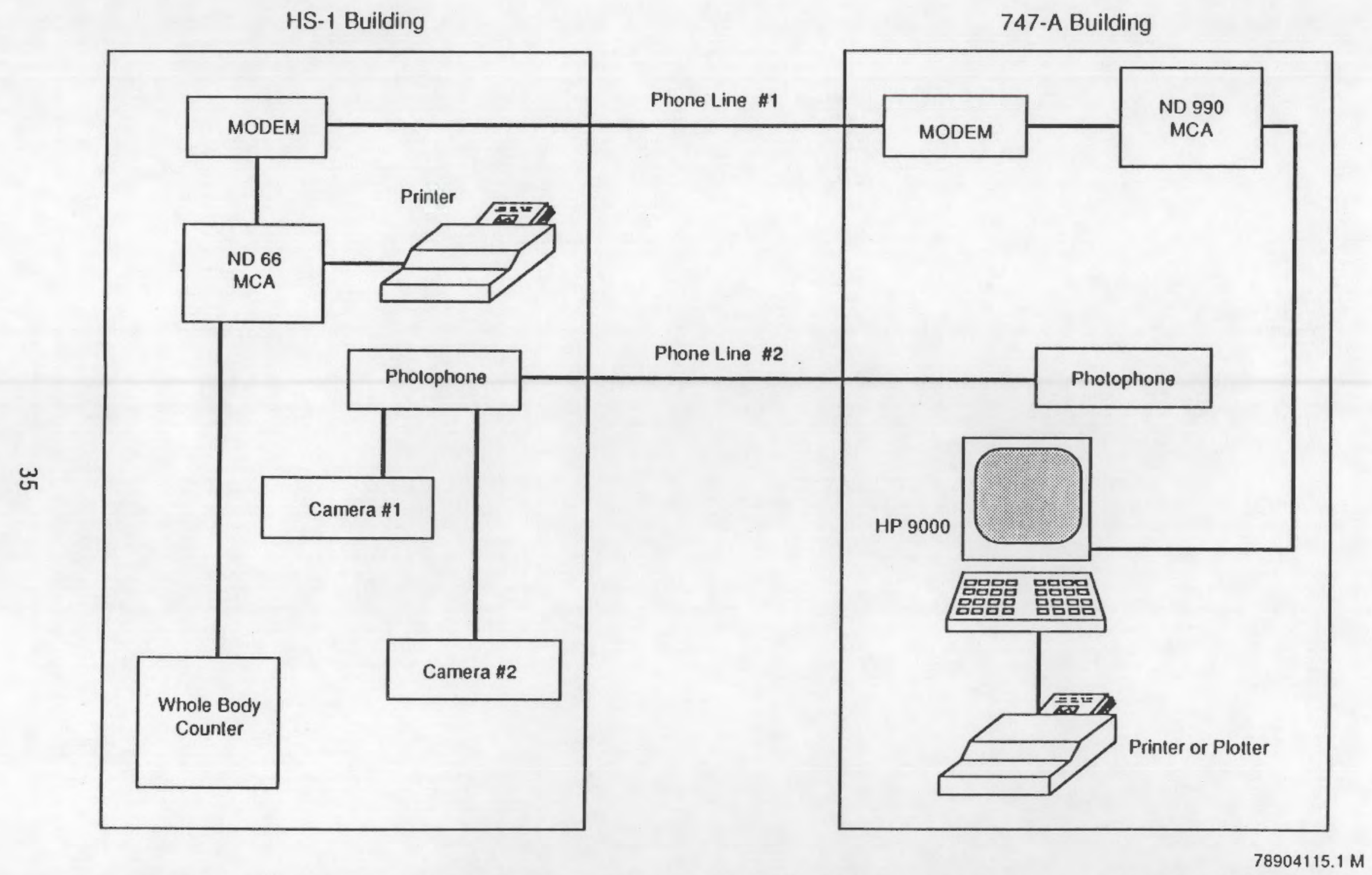

FIGURE 13. Equipment Schematic for a Remotely Operated Hhole Body Counter at the HS-1 Building 



\section{HANFORD EXTERNAL DOSIMETRY PROGRAM}

The Hanford External Dosimetry Program is a multifaceted effort involving all Hanford contractors. Dose-of-record information from external radiation for Hanford personnel is provided by this program in compliance with the requirements of DOE 5480.1, 5480.15 (DOE 1981a, 1987a) and RL 5480.11A (DOE-RL 1986). Program dosimetry services provide the means used by contractor personnel to project, control, and measure radiation doses received by personnel. Program staff also provide sitewide nuclear accident dosimetry in compliance with DOE 5480.1 requirements.

\section{ROUTINE PROGRAM}

During CY 1988, two upgraded Hanford automated reader systems were incorporated into routine processing of Hanford Site personnel dosimeters. This change was made along with the transfer of sitewide processing responsibilities from UST to PNL effective October 1, 1988. These reader systems retain many of the mechanical characteristics of the older readers, but they have significantly enhanced electronic and data processing capabilities. Each of the new readers is a stand-alone system using an IBM/AT for process control. Processing data are stored on an internal hard disk or transferred to a Bernoulli system dedicated to each reader system. These reader systems digitize the glow curve signal during processing. This information is stored for later recall and evaluation if desired. Processing data from all ring and personnel dosimeter reader systems are transferred via an ethernet system to a dedicated microvaX computer system for association with personnel identification, quality control checks, etc. One of the reader systems is pictured in Figure 14.

Each year numerous control and audit dosimeters are processed to ensure the integrity of the dosimeter processing. During 1988, 4269 control dosimeters and 3325 audit dosimeters were processed. A breakdown of the audit dosimeters is shown in Table 11.

Control charts are used to evaluate the results for each of the audit dosimeter categories. Charts are prepared for each dosimeter and radiation 


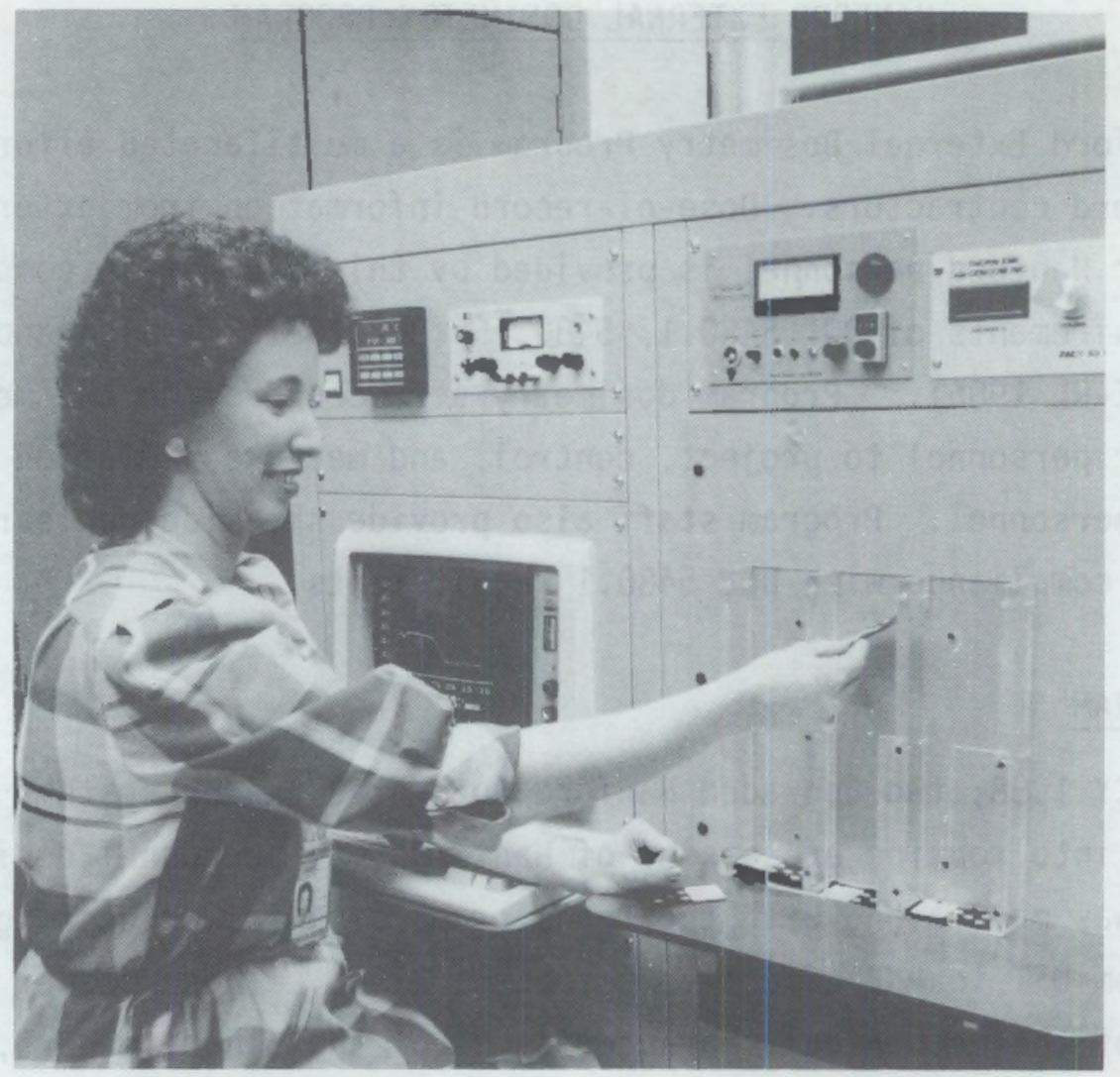

FIGURE 14. Technician Using a Reader System

type for each of the 17 dosimeter processings (monthly, quarterly, and annual) conducted each year. A quality control report is prepared for each processing. Copies are distributed to all Hanford contractor radiation protection organizations as well as to the Hanford Radiation Protection Historical Files. Copies of the control charts are also provided to the historical files.

A Hanford personal nuclear accident dosimeter (PNAD) capability was implemented during 1988. The design was based on the dosimeter used at Los Alamos National Laboratory (LANL) for many years (LANL 1981). The design of this dosimeter is summarized in Table 12. The PNAD is available in two forms; either as a stand-alone unit or attached to the bottom of the Hanford multipurpose dosimeter. An illustration of the PNAD is shown in Figure 15. 
TABLE 11. Audit Dosimeters Processed During 1988

\begin{tabular}{|c|c|c|c|c|c|}
\hline \multirow[b]{2}{*}{ Dosimeter } & \multicolumn{5}{|c|}{ Dose Category (a) } \\
\hline & Shallow & Deep & $\begin{array}{l}\text { Fast } \\
\text { Neutron }\end{array}$ & $\begin{array}{c}\text { Slow } \\
\text { Neutron }\end{array}$ & Blank \\
\hline Basic & NA & 366 & NA & NA & 170 \\
\hline Beta/photon & 180 & 120 & NA & NA & NA \\
\hline Multipurpose & 765 & 823 & 662 & 389 & 170 \\
\hline Rings & NA & 340 & NA & NA & Controls \\
\hline Two-element & 150 & 150 & NA & NA & Controls \\
\hline
\end{tabular}

(a) NA = not applicable

TABLE 12. Design Features of the Hanford Personal Nuclear Accident Dosimeter

\begin{tabular}{|c|c|c|c|}
\hline Position & Description & Diameter, $\mathrm{cm}$ & Thickness, $\mathrm{cm}$ (mil) \\
\hline 1 & Cadmium/indium & 1.1 & $0.025(10)$ \\
\hline 2 & Indium & 1.1 & $0.025(10)$ \\
\hline 3 & Sulfur & 1.2 & 0.085 (33) \\
\hline 4 & Cadmium/copper & 1.1 & $0.025(10)$ \\
\hline
\end{tabular}

(a) The cadmium enclosure that contains indium and copper foils is $0.051 \mathrm{~cm}(20 \mathrm{mil})$ thick. 


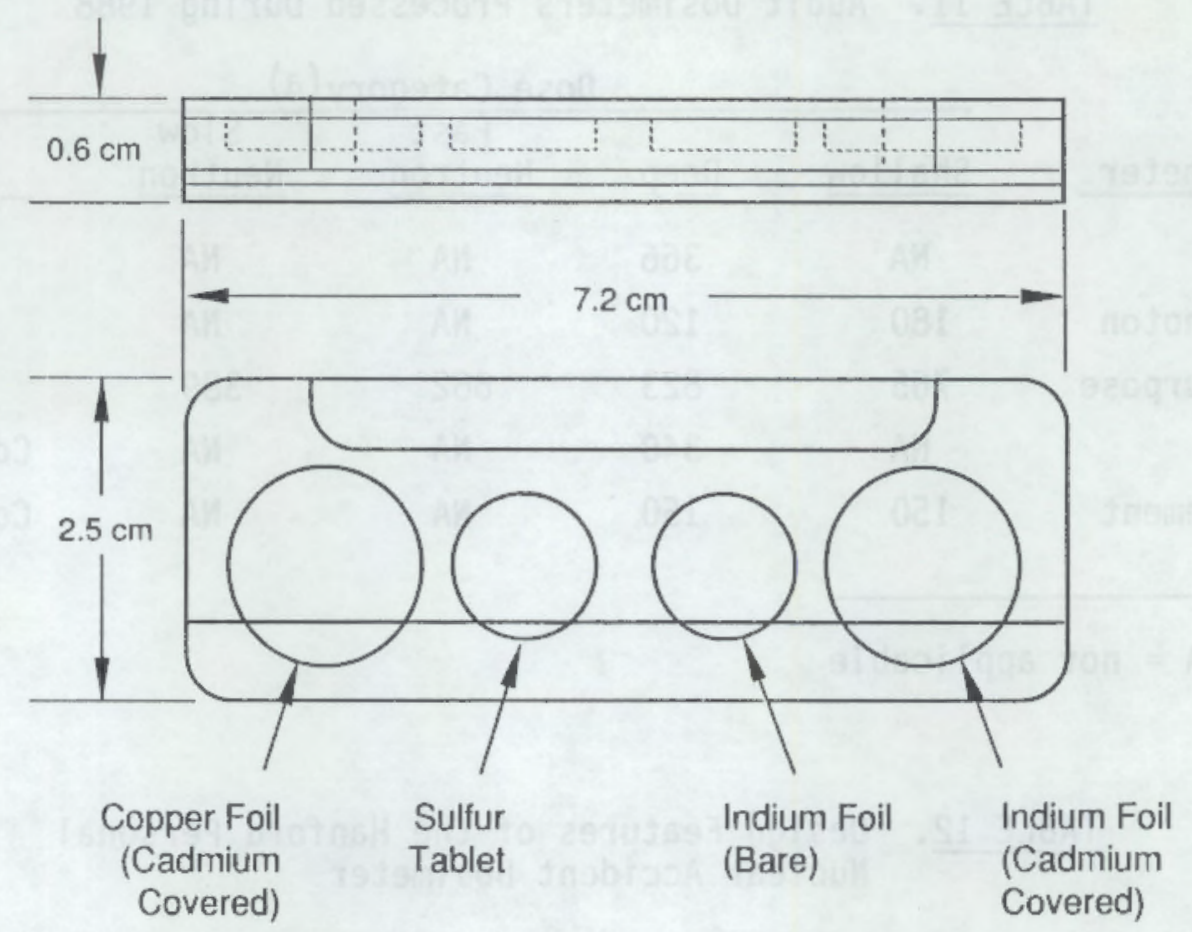

$78904115.4 M$

FIGURE 15. Hanford Personal Nuclear Accident Dosimeter

During 1988, field measurements were taken at the Plutonium Finishing Plant (PFP) before and after restart.(a)(b) The data obtained indicated nosignificant change in the neutron spectrum and thus no change in the dosimeter calibration. In addition, field gamma-spectroscopy measurements were taken at several locations in PUREX. (c) These measurements indicated that ${ }^{137}$ Cs is principally responsible for personnel exposure to photons in this

(a) Nichols, L. L. 1988. "Data Analys is for Neutron Measurements." Letter to W. A. Decker, dated May 17, 1988. Copy in the Hanford Radiation Protection Historical Files, Pacific Northwest Laboratory, Richland, Washington.

(b) Nichols, L. L. 1988. "Neutron Dose and TEPC Measurements at 234-5 Building." Letter to W. A. Decker, dated October 25, 1988. Copy in the Hanford Radiation Protection Historical Files, Pacific Northwest Laboratory, Richland, Washington.

(c) Nichols, L. L. 1988. "Photon Measurements at Purex." Letter to W. A. Decker dated August 1, 1988. Copy in the Hanford Radiation Protection Historical Files, Pacific Northwest Laboratory, Richland, Washington. 
facility and is easily measured with the Hanford personnel dosimeter. Copies of these measurements were sent to the historical file.(a)

During 1988, the following issues were reviewed by the Hanford Personnel Dosimetry Advisory Committee:

- Reporting shallow dose for basic dosimeters

- Correcting for environmental background

- Using accredited dosimeters for supplemental dosimetry

- Reporting zero dose

- Making changes to individual dose records

The Hanford Practices adopted for each of these issues by the Committee are discussed in the following subsections.

Reporting Shallow Dose

Initially, during 1988, a shallow dose was not being assessed for the results from basic dosimeters. This occurred because of the change to separate shallow- and deep-dose algorithms effective January, 1988. The Hanford Personnel Dosimetry Advisory Committee thought it was very important to maintain consistency with past results, and that it was technically important to record a skin dose when a deep dose is being recorded. The Committee recomnended reporting a shallow-dose component for basic dosimeters to enable the existing Radiological Records algorithm to automatically calculate the appropriate skin dose. After this recommendation, the few recorded dose results for 1988 were corrected. Effective with the September, 1988, monthly processing, both shallow- and deep-dose components are reported for all basic dosimeters.

Correcting for Environmental Background

The environmental background correction procedure used routinely is unable to reliably compensate dosimeters for background signals for long time

(a) Fix, J. J. 1988. "Minutes of the Meeting of the Hanford Personnel Dosimetry Advisory Committee on September 8, 1988." Letter to Distribution, dated September 12, 1988. Copy in the Hanford Radiation Protection Historical Files, Pacific Northwest Laboratory, Richland, Washington. 
periods. This is particularly important for periods beyond 1 year. It is known that the environmental dose correction calculated is inaccurate for dosimeters that are deployed for longer than 1 year. A study evaluating environmental dose correction for periods as long as 1 year is being repeated for the fourth year. The results for the previous studies have shown that, for an annual exchange, an average environmental correction of 30 to 57 mrem is most appropriate. The current procedure results in an annual dose correction of 57 mrem. The Hanford Personnel Dosimetry Advisory Comittee agreed that all dosimeters exceeding a 1-year exchange should be specially identified by appropriate notecode.(a) For nonpersonnel dosimeters, a Note Code 70 (anneal only-not worn) should be used. For personnel dosimeters, a Note Code 50, which will require special evaluation, should be used.

Using Accredited Dosimeters for Supplemental Dosimetry

The Hanford Personnel Dosimetry Advisory Comittee adopted a practice of using only accredited dosimeters for supplemental dosimetry.(b) This practice pertains to whole body monitoring. In this case, the reported shallowand deep-dose components for supplemental dosimeters are evaluated in the same manner as the dose components for the official whole body dosimeter. At a later meeting, (c) supplemental extremity dosimeter monitoring was discussed. Currently, there is no program for accrediting extremity dosimeters, however a pilot progran is being tested. Regardless of the type of dosimeter used for extremity monitoring, the shallow-dose component should be recorded.

(a) Fix, J. J. 1988. "Minutes of the Hanford Personnel Dosimetry Advisory Committee on September 8, 1988." Letter to Distribution, dated

September 12, 1988. Copy in the Hanford Radiation Protection Historical Files, Pacific Northwest Laboratory, Richland, Washington.

(b) Fix, J. J. 1988. "Minutes of the Hanford Personnel Dosimetry Advisory Committee on January 14, 1988." Letter to Distribution, dated January 22, 1988. Copy in the Hanford Radiation Protection Historical Files, Pacific Northwest Laboratory, Richland, Washington.

(c) Sula, M. J., and J. J. Fix. 1988. "Minutes of the Hanford Personnel Dosimetry Advisory Committee on December 8, 1988." Letter to Distribution, dated December 9,1988 . Copy in the Hanford Radiation Protection Historical Files, Pacific Northwest Laboratory, Richland, Washington. 
Reporting Zero Dose

The Hanford Personnel Dosimetry Advisory Comittee reviewed the Hanford practice of reporting dose measured with personnel dosimeters. (c) Recently, the reporting of a zero for dose received during a tour of Hanford Operations was questioned. In this case, an individual carried a personal small Geiger counter during the tour and it, as well as the Hanford dosimeters used by tour members, showed an average dose of approximately 2 mrem. The calculation of doses to be reported is a longstanding practice. This practice involves calculating shallow-, deep-, fast-neutron-, and slow-neutron-dose components in units of centirem, adding 0.5 centirem to each dose component, and truncating and multiplying by 10 to determine the millirem dose. Before the dose is calculated, an average background value is subtracted for each chip position based on the processing of many nondosed dosimeters. In the case under review, a zero dose was reported for the entire tour group because 2 mrem is less than the 5 mrem necessary to result in a reported dose of $10 \mathrm{mrem}$. An analysis of the Hanford procedure of rounding doses was conducted previously and presented to the Committee(a) for consideration in response to an outside technical comittee appraisal of the External Dosimetry Program done during 1984 by representatives from Rocky Flats Plant, Lawrence Livermore National Laboratory, and the University of California at Davis. (b) This analysis indicated no significant difference in individual dosimeter results or the cumulative dose per contractor between the Hanford procedure and the reporting of doses rounded to the nearest millirem with the exception of the slow-neutron-dose category. For slow neutrons, an increase was observed in the cumulative dose per contractor because of the summation of many small slow-neutron doses. These slow-neutron doses are an insignificant addition to the relatively large fast-neutron dose and, occasionally deep dose, which is being reported. After substantial debate, the Committee

(a) Fix, J. J. 1987. "Information Pertaining to the Hanford Method of Personnel Dosimetry Dose Report." Letter to Distribution, dated June 24, 1987. Copy in the Hanford Radiation Protection Historical Files, Pacific Northwest Laboratory, Richland, Washington.

(b) C. Lagerquist, T. J. Powell, and J. Smathers. 1984. Letter to D. E. Hadlock on results of the Technical Committee Appraisal of Hanford's External Dosimetry Program. Copy in the Hanford Radiation Protection Historical Files, Pacific Northwest Laboratory, Richland, Washington. 
Committee recomended that, for radiological exposure reports to individuals, a zero be defined as indicating that the dosimeter measured a dose of less than 5 mrem. The historical Hanford method of calculating doses would continue for all Hanford personnel.

Making Changes to Individual Dose Records

The Hanford Personnel Dosimetry Advisory Committee reviewed the situation where changes are made to individual dose records and recommended that the changes be reviewed with the individual involved.(a) The Committee further recomended that the dose record should show that this review was conducted. To accomplish this, all letters, memoranda, and Investigation of Dose Results forwarded to Radiological Records are countersigned by the individual involved to show that the change was explained and that he/she has been notified of the change. If the individual refuses to sign the change document or is no longer employed on site, the change is still made. The reason for the change is fully explained and the individual's refusal to sign or nonavailability is noted on the change document.

\section{SUPPORTING INVESTIGATIONS AND STUDIES}

Studies were conducted during 1988 to upgrade program documentation, resolve technical issues, and improve $Q C$ of dosimeter fabrication, use, processing, or dose assessment as discussed in the following subsections.

Combination CR-39/Hanford Albedo Dosimeter

Laboratory evaluation of the dosimeter angular response and lower level of detection capabilities for a prototype CR-39/Hanford albedo dosimeter was conducted. In addition, a 4-month parallel field test and intercomparison of CR-39 and albedo dosimeter components was evaluated. The recomendations of DOE/EH-0027 (DOE 1986) were used to assess the lower level of detection for

(a) Fix, J. J. 1988. "Minutes of the Hanford Personnel Dosimetry Advisory Committee on September 8, 1988." Letter to Distribution, dated

September 12, 1988; and Sula, M. J., and J. J. Fix. 1988. "Minutes of the Hanford Personnel Dosimetry Advisory Committee on December 8, 1988." Letter to Distribution, dated December 9, 1988. Copies in the Hanford Radiation Protection Historical Files, Pacific Northwest Laboratory, Richland, Washington. 
the CR-39 dosimeter. For either moderated or bare californium exposures, the detection level for CR-39 was approximately 5 mrem. For the field comparison, the average performance of either the CR-39 or albedo dosimeter component was satisfactory. However, an analys is of dosimeter outliers indicated an unacceptable frequency of large variances between the two CR-39 dosimeter foils. This was attributed to a material QC problem. The results of the albedo dosimeter component were the same as the results reported in the 1987 annual report (Lyon et al. 1988).

Dosimeter Performance Testing

Pacific Northwest Laboratory participated in a voluntary DOE Laboratory Accreditation Program (DOELAP) performance test during 1988 in preparation for formal testing during 1989. Performance coefficient results are shown in Table 13 for shallow and deep doses, respectively (DOE 1986). Each of the basic, multipurpose, and beta/photon dosimeters failed one category. Overall, the performance of the Hanford dosimeters was very good. Generally, the performance coefficient was well within the required tolerance. Marginal performance was shown for all accident-level categories and resulted in the failure of this category for the basic dosimeter. This problem was expected because of the very high doses received by these dosimeters (up to 500 rem). The beta/photon dosimeter failed the mixed low-energy and high-energy photon category. This was an algorithm problem that was subsequently corrected. The part of the code in question must be capable of calculating high-energy photon, low-energy photon, and beta radiation, and mixtures of each radiation. The perfomance of the algorithm was very good for all other categories. The failure of the fast-neutron category for the multipurpose dosimeter is due to a $-30 \%$ bias in the calibration factor used for the bare $252 \mathrm{Cf}$ source used in the irradiations. The cause for this was never fully resolved. Subsequent tests have shown excellent agreement. Immediately prior to the DOELAP test, a special set of 15 dosimeters was irradiated to confirm the NIST-traceable fast-neutron calibration. The calibration used in the test was based on these results. It is important to note that the routine calibration for fast neutrons at Hanford is based on field neutron measurements at applicable facilities and all evidence indicates that the routine calibration of fast-neutron doses for Hanford facilities is accurate. 
TABLE 13. Shallow- and Deep-Dose Performance Test Data

DOELAP Category Description

Shal low Dose Component
DOELAP

Criterion
Performance(a)

Basic HMPD HBPD
Low-energy photons, plutonium environments

High-energy photons, ${ }^{137} \mathrm{Cs}$

Beta particles, $90 \mathrm{Sr}$

Mixtures

Low-energy photons + high-energy photons

Low-energy photons + beta

High-energy photons + beta

Deep Dose Component

Low-energy photons, accident levels

High-energy photons, accident levels

Low-energy photons, plutonium environments

High-energy photons, ${ }^{137} \mathrm{Cs}$

Neutrons, unmoderated 252Cf

Mixtures

Low-energy photons + high-energy photons

Low-energy photons + beta

Low-energy photons + neutrons

High-energy photons + beta

High-energy photons + neutrons
0.3

0.15

0.01

0.3

0.07

0.15

0.3

0.06
0.4
0.14
0.30
0.15
0.4
0.25

$\begin{array}{llll}0.3 & & 0.29 & 0.12 \\ 0.3 & 0.31(b) & 0.22 & 0.22 \\ 0.3 & & 0.05 & 0.17 \\ 0.3 & 0.10 & 0.08 & 0.18 \\ 0.3 & & 0.47(b)\end{array}$

0.4

0.16

$0.51(b)$

0.4

0.19

0.4

0.16

0.4

0.17

0.4

0.12

(a) Performance result for Hanford basic, Hanford multipurpose dosimeter (HMPD) and Hanford beta/photon dosimeter (HBPD).

(b) Did not pass test criterion for category.

\section{DOCUMENTATION}

Formal documentation of the Hanford External Dosimetry Program is contained in PNL's internal procedures for criticality alarms and nuclear accident dosimeters and on external dosimetry. In addition to these documents, several internal technical documents are used by program staff to document the design, algorithm, calibration, and dose-response characteristics of the different dosimeters, as well as procedures for evaluating the nuclear- 
accident dosimeter. For significant program issues, letter reports are prepared and submitted to the Hanford Personnel Dosimetry Advisory Comittee for review and comment. Copies are included in the minutes of these Committee meetings and provided to the Hanford Radiation Protection Historical Files, maintained by PNL under the Hanford Radiological Records Program.

\section{PRESENTATIONS}

Program staff made the following presentations during 1988:

1. Fix, J. J. 1988. "Extremity Dosimetry Issues." Invited presentation to the 2nd Annual Harshaw Users Conference, November 13-16, Myrtle Beach, South Carolina.

2. Fix, J. J. 1988. "Methodology to Estimate Overall Error in Occupational Dose." Paper presented at the Annual Health Physics Society Meeting, July 4-8, Boston, Massachusetts.

3. Fix, J. J. 1988. "Historical Overview of Hanford Personnel Dosimetry." Presentation to Hanford Health and Mortality Oversight Cormittee, September 14-15, Seattle, Washington.

4. Nichols, L. L., and J. J. Fix. 1988. "An Automated Area Dosimeter for Beta and Gamma Radiation." Paper presented at the Second Conference on Radiation Protection and Dosimetry, October 31November 3, Orlando, Florida.

PROGRAM-RELATED PROFESSIONAL ACTIVITIES

Program staff were involved in several program-related external professional activities:

1. Fix, J. J.--Chairman of Heaith Physics Society Standards Conmittee Working Group to develop a standard titled "How to Estimate the Overall Accuracy in Occupational Dose Determinations."

2. Fix, J. J.--Chairman of DOELAP Oversight Board as identified in DOE $5480.15(1987)$.

3. Fix, J. J.--Member of Health Physics Society Standards Committee Working Group to revise American National Standards Institute (ANSI) Standard N319 titled "Personnel Neutron Dosimeters (Neutron Energies Less Than $20 \mathrm{MeV}$ )."

4. Rathbun, L. A.--Member of the American Society of Testing and Materials (ASTM) Task Group E-10-04-16 working to write a standard titled "How to Perform Field Measurements of Beta Spectra." 



\section{INSTRUMENT CALIBRATION AND EVALUATION PROGRAM}

The operation of a complete radiation protection instrument program is an integral part of Hanford radiation protection programs. The Instrument Calibration and Evaluation Program provides a complete radiation protection instrument service, thereby equipping the Hanford contractors with quality, reliable, and accurate instrumentation capable of performing at the level necessary to ensure personnel safety as required by DOE 5480.11 (1989). Calibrations are performed using the guidance in ANSI N323-1978 (ANSI 1978). The routine program activities fall under the five base tasks that comprise the program: 1) Routine Portable Instrument Pool, 2) Hanford Instrument Evaluation Program, 3) Deployment of High-Range Cutie Pies, 4) Instrument Manual Update, and 5) Documentation of the History of Hanford Instruments. These and other supporting tasks performed during $\mathrm{CY} 1988$ are discussed in the following subsections.

\section{ROUTINE PROGRAM}

The routine program provides for a complete radiation protection instrument program. This consists of procuring new and replacement instruments; overseeing an instrument pickup and delivery service; keeping records; and surveying, decontaminating, maintaining, and calibrating instruments. The routine program also includes the following:

- maintaining traceability of radiological and electronic calibration systems to the NIST

- operating a program to service radiation protection emergency kits

- modifying and updating written calibration procedures as new instruments are introduced and calibration techniques are improved

- procuring, acceptance testing, calibrating, and distributing pencil dosimeters

- performing specification development and acceptance testing on all instruments purchased for pool use and as required by Hanford contractors. 
Routine Portable Instrument Pool

Table 14 summarizes the usage of portable instruments on the Hanford Site during $\mathrm{CY} 1988$. For each contractor, the types of instruments, number of instruments, and the percent of the total number of instruments are listed (i.e., PHL, KEH, and WHC 100, 200, and 300/400 Areas).

During 1988, a number of new instruments were procured to replace instruments damaged or disposed of as a result of contamination. Ten Eberline Model R0-3B cutie pies (CPs) were procured. Fifty Bicron count rate meters were also received. Seventy-five pancake probes were fabricated by PNL Craft Services and are now in the instrument pool.

Hanford Instrument Evaluation Program

Each year many new instruments become available from the manufacturers. The Hanford Instrument Evaluation Program has been established to evaluate, for use at Hanford, instruments designated by the Hanford Instrument Evaluation Committee, which includes representatives from each Hanford contractor.

Fifteen portable ion-chamber instruments were purchased during FY 1987 for evaluation against the Eberline R0-3B CP by field personnel. These consisted of five Eberline Model R0-2s, five Bicron Model RSO-5s, and five Victoreen Model 450s. The Model RO-2s and the RSO-5s are still in the field for use and evaluation. The five fully modified Model 450-Bs, which also include meter dial lights, were received from victoreen in 1988 and are being sent to the field.

Deployment of High-Range Cutie Pies

The high-range cutie pie (HRCP) is a pistol-shaped, air-filled ionization chamber used to measure high levels (up to $50 \mathrm{krem} / \mathrm{h}$ ) of beta and gamma radiation. The HRCP Program had three milestones for 1988. The first was to deliver the FY 1987 Model HRCPS to the field for use. This was initiated during the second quarter of FY 1988 and a number of HRCP instruments have been sent to the field. The second milestone was to complete the upgrade of the FY 1985 Model HRCPs; work on this began during the last quarter of the FY 1988 and is approximately $50 \%$ complete. The third milestone was to make 
TABLE 14. Portable Instrument Usage for Calendar Year 1988

\begin{tabular}{|c|c|c|c|c|c|c|c|c|c|c|}
\hline \multirow[b]{3}{*}{$\begin{array}{l}\text { Instrunent } \\
\text { Iype. }\end{array}$} & \multirow{2}{*}{\multicolumn{2}{|c|}{ KEH }} & \multicolumn{6}{|c|}{ Test inghouse } & \multirow{2}{*}{\multicolumn{2}{|c|}{$P$ P }} \\
\hline & & & \multicolumn{2}{|c|}{100 Ares } & \multicolumn{2}{|c|}{200 Area } & \multicolumn{2}{|c|}{300 and 400 Areas } & & \\
\hline & $\begin{array}{l}\text { Nusber of } \\
\text { Instrumente }\end{array}$ & $\begin{array}{l}\text { Porcent of } \\
\text { Xaiser Total } \\
\end{array}$ & $\begin{array}{l}\text { Nunber of } \\
\text { Instrunente }\end{array}$ & $\begin{array}{c}\text { Percent of } \\
100 \text { Area Total }\end{array}$ & $\begin{array}{l}\text { Number of } \\
\text { Inetrueents }\end{array}$ & $\begin{array}{l}\text { Percent of } \\
200 \text { Ares Total }\end{array}$ & $\begin{array}{l}\text { Nuaber of } \\
\text { Instrunente }\end{array}$ & $\begin{array}{l}\text { Percent of } \\
300 \text { and } 400 \\
\text { Areas Total }\end{array}$ & $\begin{array}{l}\text { Nuber of } \\
\text { Instrunente }\end{array}$ & $\begin{array}{l}\text { Percent of } \\
\text { PhL Total }\end{array}$ \\
\hline \multicolumn{11}{|l|}{$\mathbf{E y}$} \\
\hline $\mathbf{C P}$ & B & $\mathbf{5}$ & 207 & 18 & 1218 & 20 & 160 & 17 & $\mathbf{5 0 1}$ & 15 \\
\hline DAD & 150 & 95 & 950 & 22 & 85 & 1 & 4 & 0 & 73 & 2 \\
\hline EF & & & 440 & $\mathbf{x}$ & 1730 & 20 & 244 & 25 & 1175 & 94 \\
\hline TPC & & & 4 & 0 & 23 & 0 & 4 & 0 & 3 & 1 \\
\hline LPC & & & & & & & 3 & 0 & 2 & 0 \\
\hline $\mathrm{HPC}$ & & & 31 & 2 & $\mathbf{6}$ & 1 & .80 & 8 & $\mathbf{s}$ & 0 \\
\hline$x \subset P$ & & & $\bullet$ & 1 & 25 & 0 & & & 2 & 0 \\
\hline G SHOOPY & & & $\bullet$ & 1 & 70 & 1 & 40 & 4 & 48 & 1 \\
\hline F PN & & & $\pi$ & $\mathbf{6}$ & 895 & 14 & 194 & 14 & 488 & 14 \\
\hline س & & & 4 & 0 & 101 & $\mathbf{3}$ & 26 & 8 & 148 & 4 \\
\hline PAMCAKE & & & 864 & 22 & 1380 & 22 & 268 & 28 & 778 & 23 \\
\hline Ш & & & 1 & 0 & s & 0 & & & 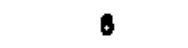 & 0 \\
\hline HRCP & & & 15 & 1 & 22 & 0 & 6 & 1 & 24 & 1 \\
\hline BECP & & & $\boldsymbol{8}$ & 0 & 41 & 1 & 24 & 2 & 67 & 3 \\
\hline PAC-8 & & & 23 & 1 & 394 & 6 & 1 & 0 & $\mathbf{6 0}$ & 2 \\
\hline BNCP & & & & & 7 & 0 & $\mathbf{s}$ & 0 & 17 & 0 \\
\hline \multicolumn{11}{|l|}{ TOTAL } \\
\hline \multicolumn{11}{|l|}{ INSTRasegits } \\
\hline CONTRACTOR & 107 & & 1010 & & 6139 & & 974 & & 941 & \\
\hline \multicolumn{11}{|l|}{ PERCET OF } \\
\hline POO TOTAL & 1 & & 13 & & 60 & & 8 & & 28 & \\
\hline
\end{tabular}


improvements in the control switches for all units; the improvement process was established in April and the new switches will be added to the 1985 units as they are assembled. The 1987 switches will be upgraded as the units are returned from the field for calibration or repair.

Difficulties are still being encountered in the form of illegal characters being present in the calibration programable read-only memories (PROMs), which allow for a "burn-in" of the new factors. There is also still a problem with some units trying to switch from Range 3 to 4 at too low an exposure rate. Further action with Victoreen in the form of warranty repair may be required.

Instrument Manual Update

During 1988, two new sections of the instrument manual were completed. The sections addressed two different types of bench monitors: the Eberline Model RM-19 and the Ludlum Model 177.

Documentation of the History of Hanford Instruments

A report documenting the use and calibration of portable health physics instrumentation on the Hanford Site was prepared, reviewed, and is soon to be published. (a) This document reviews the early development of and provides the historical background for the use of specific types of instrumentation and the calibration equipment and techniques employed over the years of site operation. Two milestones are associated with this task: the first milestone was to complete the data-gathering by the end of June, 1988, and the second was to complete the document by the end of December, 1988. Initial delays were encountered in the process of obtaining the services of qualified personnel; however, by the end of the calendar year, the major sections of the document had been completed and were in the process of being peer reviewed. The document is scheduled to be published in March, 1989.

(a) Howell, W. P., C. D. Corbit, J. L. Kenoyer, L. V. Zuerner, M. L. Kress, D. M. Fleming, K. L. Swinth, and H. W. Dehaven. Historical Review of Portable Health Physics Instruments and Their Use in Radiation Protection Programs at Hanford, 1944 Through 1988. (In Press). Pacific Northwest Laboratory, Richland, Washington. 
SUPPORTING TASKS

Three additional supporting tasks were performed during $\mathrm{CY} 1988$. Alpha Continuous Air Monitor Calibration

Calibration of WHC instruments from the 200 Area by PNL personnel began in July. By September, 25\% of the available 200-Area WHC units were being sent to the 318 Building for calibration. This percentage is scheduled to be maintained into 1989 .

Work continued to be performed in 1988 on the upgrade of the alpha continuous air monitor (CAM) calibration procedure for use as a sitewide procedure. The problem of the interference of radon, thoron, and their progeny in the measurement of $239 \mathrm{Pu}$ with the current alpha CAMs was also under continued investigation. Extended air-monitoring samples were obtained and analyzed with respect to the specific alpha energies associated with the natural background and the contribution of those energies to the plutonium energy interval. Currently, 25\% of the counts observed in the radon energy window are subtracted from the number of counts observed in the plutonium window. Other subtraction percentages were evaluated and it appears that, for a long monitoring interval, the $25 \%$ factor used is both conservative and suitable. The effect of filters becoming loaded with dust during the sampling on the shift of the energy peaks and the feasibility of electronically changing the alarm set point during high-radon episodes were also investigated. When the CAM units were tested in the laboratory, the resolution of the alpha-energy peaks was seen to be affected by the filter loading with dust. As the filter became loaded with dust, the resolution became better because the radon particulates impacted on the surface of the dust and did not become imbedded in the filter. It was also determined that the resolution changes could be compensated for by using correction factors based on the pressure drop across the filter at the time of monitoring. The capability of electronically changing the set point as the radon background changed was developed and tested. The feasibility of using this method was determined to be low after the filter loading results were obtained. 
Pocket Alarming Dosimeters for the 200 Area Fire Station

Forty-eight pocket alarming dosimeters and two programmers were received in April. After a number of the units failed an inspection test of workmanship, the entire shipment was returned to the distributor. The units were repaired and returned to PNL in September. All unit but one passed workmanship and functional testing. The one unit was subsequently repaired and all units have been put into service.

Check Sources for Eberline Geiger-Mueller Instruments

Approximately 150 natural uranium check sources were secured into holders and located on the inside of Eberline Geiger-Mueller instruments to date. These sources will allow for an in-the-field performance check of the instruments as required by ANSI N323-1978 (1978).

PROGRAM-RELATED PROFESSIONAL ACTIVITIES

The program-related professional memberships of the staff during 1988 are listed here.

1. D. M. Fleming--Member of the Task Group 4 writing a National Council on Radiation Protection and Measurements (NCRP) Handbook titled in "Calibration of Survey Instruments for the Assessment of Ionizing Radiation Fields and Radioactive Surface Contamination."

2. D. M. Fleming--Member of the ANSI Working Group N42.17 writing the standard titled "Performance Specifications for Health Physics Instrumentation-Portable Instrumentation for Use in Normal Environmental Conditions."

3. J. L. Kenoyer--Consultant to the ANS1 Working Group N42.17 writing the standard titled "Performance Specifications for Health Physics Instrumentation-Portable Instrumentation for Use in Normal Environmental Conditions."

4. J. L. Kenoyer--Member of the National Standards Board-7 Working Group on the Calibration of Portable Health Physics Instruments.

5. F. E. Owen--Member of the Working Group American Nuclear Society/ Health Physics Society Standards Conmittee (ANS/HPPSSC) ANSI 6.8 writing the standard titled "Area and Process Monitors." 


\section{RADIATION STANDARDS AND CALIBRATIONS PROJECT}

The Radiation Standards and Calibrations Project maintains radiological standards, special instrument and dosimeter response-characterizing equipment, and calibration data-handling equipment at Hanford. This activity provides the means to characterize response to various radiation fields encountered at Hanford and ensures that calibration fields are described in accordance with recomended standards and guides. This activity includes quality assurance (QA) responsibilities for routine calibration of instruments and dosimeters. The project routinely

- reviews calibration standards, regulations, and handbooks

- ensures that the calibrations procedures used are in agreenent with technically accepted methods

- maintains basic radioactive sources and instruments that serve as radiological standards

- provides traceability of the calibration sources to the NIST

- maintains a data management system for instrument repair and calibration records.

Project activities conducted during $c \gamma 1988$ are discussed in the following subsections.

\section{ROUTINE PROGRAM}

Two major functions comprise the project's routine program: 1) maintenance of standards and capabilities and 2) maintenance of the data management system. These functions and any related improvements are discussed in the following subsections.

Maintenance of Standards and Capabilities

Various radioactive sources are used routinely for dosimeter and instrument calibrations. The "maintenance of standards" task provides for NIST- traceable calibrations of the sources used in calibrating radiationdetection devices. Room 6 in the 318 Building houses a pneumatic sourcetransfer and -storage system, which contains $137 \mathrm{Cs}$ and $60 \mathrm{Co}$ photon sources and two levels of $252 \mathrm{Cf}$ neutron sources used for low-scatter irradiation 
geometries. The photon sources are calibrated periodically. Each source is measured in the most commonly used geometries. During 1988, agreement among the measurement data was within $\pm 2 \%$ of the values expected due to decay of the sources. Calibration checks of the $252 \mathrm{Cf}$ sources are performed by comparing them with a plutonium-beryllium (Pu-Be) source. Reference calibration data were collected in 1988 to allow for the use of the free-field Pu-Be neutron spectrum as the source standard.

A high-level photon irradiator is housed in Room 8 of the 318 Building. The system consists of a highly shielded source-storage mechanism, a turntable for source selection, a closed-loop source-transport system, and a well-collimated irradiator with a conical beam port. The selected source is transported pneumatically to the irradiation position. An operational control panel is positioned outside the irradiation room and is well shielded against radiation exposure. A rail system is installed as a trolley support track over a $6-m$ range on the floor parallel to the beam axis. A laser centered on the beam axis is intersected by a cross laser at the $100-\mathrm{cm}$ distance to provide alignment capabilities. All four sources in the highlevel irradiator are calibrated annually. Measured exposure rates in 1988 were within tolerance of the values $(2 \%)$ expected due to decay of the sources. The calibration measurements are performed using measurement and test equipment that have certified traceability to the NIST.

Four wells containing isotopic sources are housed in Room 121 of the 318 Building. These wells are used primarily in the routine calibration program for portable instruments. Computer programs are used to control a trolley system that moves the source vertically to any desired point within the 9-m depth, based on the calibration of the wells. The programs allow for selection of either the desired exposure, the dose-equivalent rate, or the distance with known rate. The program is also capable of stepping through the exposure rate points of the desired instrument calibration with only minimal operator involvement. The distance from the plane of the well's surface to the detector center is entered as an offset and is included in the selected overall distance. All wells receive extensive annual calibration in addition to the less extensive quarterly calibration checks that are directly related to routinely used instrument calibration points. No unusual variances were 
observed from the expected decay of source emissions due to isotopic halflives in 1988.

Improvements to the Maintenance of Standards and Calibrations Functions

The steadily decreasing radiation output of the large $252 \mathrm{Cf}$ source in Room 6 was beginning to cause the irradiation times for many calibrations to become excessively long. A suitable replacement source was located at 0ak Ridge National Laboratory, and arrangements were made for the loan of this source for a period of 5 years. Because the source had a configuration somewhat different than our present source, considerable effort was expended on the redesign of the capsule that will transport the source through the pneumatic system. A redesigned dumny capsule was successfully tested in the system. Final encapsulation of the new source should occur in early 1989. After encapsulation, it should be sent to the NIST for an absolute calibration of neutron output before it is installed in the system.

During the year, major redesign of the north irradiation station in Room 6 began. This station is used primarily for the calibration of dosimeters. The redesign should make use of the station more convenient and will minimize extraneous material in the area, which contributes to scattering of the primary radiation beam when a source is being used.

Maintenance of the Data Management System

Maintenance and updating of the process-control system, including the Hewlett Packard HP-9000 computer, its peripherals, and the data management software comprise the data management system.

Improvements to the Maintenance of the Data Management System Function

The changeover to an HP-9000 computer was completed in 1988 when the last of the instrument databases was transferred. This process took place with a minimum of problems. Two new data entry stations for Rooms 110 and 117 were added. Several older unserviceable terminals were replaced. Plans were in hand late in 1988 to further upgrade the HP-9000 computer.

The database software was modified on a number of occasions during the year. A customer billing program was implemented. The database was modified to include non-DOE-sponsored instruments and nonroutine calibrations, as well 
as air-monitoring and nuclear criticality detectors. Procedures on the use of the database were distributed to all users of the system.

SUPPORT ING INVESTIGATIONS AND STUDIES

Three special studies were performed to help improve the QA programs for dosimeter and instrument calibrations.

Measurement Quality Assurance for Photon Beams

In order to verify the consistency (or traceability) of PNL Calibrations measurements with national standards, PNL Calibrations is again participating in a measurement quality assurance (MOA) program for photons with the MIST. Under this program, the NIST sends Calibrations a high-quality transport ionization chamber whose response to radiation is not known by Calibrations staff. Calibrations staff then determine the response (signal per unit of radiation) for the transfer standard and report the results. The NIST then provides a report of the ratio of PNL's measured response obtained with the national standard. This process is carried out periodically to assure that the Calibrations measurements stay within agreed-upon control limits (usually 28 ). The MOA testing for photons occurs every other year. The testing protocol began late in 1988 and is expected to be completed in early 1989. Monte Carlo Simulations of Neutron Transport

There was concern that moderator evaporation would have a significant effect on the energy spectrum of the $252 \mathrm{Cf}$ source. Changes in the energy spectrum could introduce inaccuracies in dosimeter and instrument calibrations. A study was performed to determine if any effect would occur.

Transport of neutrons from a source is characterized by travel along straight paths between widely spaced collision points. Upon collision, the particle may be absorbed or else scattered into a new direction and energy. The so-called Monte Carlo or stochastic method simulates this behavior, and then obtains the flux density (and dose) at a point by averaging the scores from thousands of individual particle tracks. Usually 10,000 to 100,000 source particles are generated and their histories are computed. The use of a high-speed digital computer such as the HP-9000 greatly facilitates these 
calculations. This method was used to determine the effect of moderator evaporation on the energy spectrum of the $252 \mathrm{Cf}$ source.

The Monte Carlo simulations performed for a variety of scenarios led to the conclusion that only a catastrophic loss of moderator would greatly change the energy spectrum of the source.

Evaluation of Instrument Bar Code Labels

Work continued on the feasibility of using bar code labels to identify instruments. A bar code reader was ordered and will be used to investigate the use of these labels with pencil dosimeters. 



\section{HANFORD RADIOLOGICAL RECORDS PROGRAM}

The Hanford Radiological Records Progran supports the DOE-RL and Hanford contractor radiation protection programs by preserving and administering radiological exposure records for all Hanford workers and visitors, past and present. In addition, the program is responsible for the Hanford Radiation Protection Historical Files, Hanford Radiological Incident File, and the operation of the computer systems and equipment necessary to input, store, and retrieve the records and produce the required reports.

The records progran uses the ORE System, which includes a database with the personnel exposure data that are readily retrievable. The ORE system also includes all of the supporting exposure documentation on microfilm that is indexed into a computer-assisted retrieval (CAR) system. The CAR system allows for rapid retrieval of the documents for any individual, using identifiers including payroll number, social security number, and/or name.

The historical records include documents, such as policies, procedures, reports, important communications, etc., that define the radiological dosimetry and protection programs during its history. The historical records are microfilmed and indexed into a second CAR system. These records are retrievable by author, date or range of dates, document number (if applicable). title, and up to three key words.

The incident file contains a record of all available radiological incidents that have occurred at Hanford since 1945. They are located in the Radiological Records Library in a chronological file.

The program is operated under the applicable sections of ANSI N13.6-1972 (1972), DOE 1300.1, 1324.2A, 5480.1A, 5480.11, and 5484.1, Chg. 3 (1980, 1988, 1981, 1989, 1987c) as assigned by the Hanford Site Services Handbook (DOE-RL 1983). It also complies with the applicable sections of the Privacy Act (1974) and the Freedom of Information Act (1966).

\section{ROUTINE PROGRAM}

The Hanford Radiological Records Program is organized as three major functional areas: data handling, report issuance, and the library. The 
data-handling function provides for the entry of data elements into the ORE database and for the validation of all data entry. Validation is accomplished by establishing audits to be matched to entries of results, resolving unmatched results, and interacting directly with contractor personnel.

The report-issuance function generates and issues routine exposure status reports to the contractors, quarterly man-rem and annual statistical reports to DOE, annual reports to employees, and special reports requested by former employees, as well as those requested by the contractors and DOE-RL. Both the data-handling and report-issuance functions are performed by the Radiological Records data processing center. This function requires close liaison with DOE-RL, the contractors, and other personnel dosimetry functions.

The library function maintains the individual exposure records that are not reducible to database elements, as well as the Hanford Radiation Protection Historical files and radiological incident file. The library staff file and retrieve current hard-copy documents, prepare documents for long-term storage, and track and account for the documents through the microfilming and indexing process. The library contains the individual exposure record documentation for all Hanford personnel since 1945 (almost five million microforms). There are also some exposure records remaining from the duPont era. These and the historical file microforms are retrievable through the two CAR systems that are maintained by the library staff.

Although the results from the dosimeter and excreta processing, as well as the in vivo counts, are received by electronic transmission or magnetic tape, a large amount of data that is placed in the records is received in hard-copy form. These data are entered manually by the data processing center staff. The hard copies are then sent to the library for entry into the CAR system. Table 15 presents statistical information on many of the documents that are entered into the database and microfilmed and indexed into the CAR system. 
IABLE 15. Records Activity for Calendar Year 1988 Document

Number

Personal Radiation Exposure History Form (used to 2,140 document exposure history prior to Hanford employment)

Employee and Dosimetry Change Form (used to document personnel or dosimetry changes)

Employee and Dosimetry Change Form (used to document 3,956 employee terminations)

Temporary Dosineter Assignment Form (used for visitors and employees that forgot their dosimeters)

14,070

Investigation of Dosimeter Result Form (used to 4,448 estimate exposure for lost, damaged, or otherwise suspect dosimeter results)

Special Process Form (used to document data for specially processed dosimeters)

Training documents (used to document radiological training of personnel)

Request for special excreta sample analyses (used to 2,505 initiate the collection of samples for analysis)

Offsite requests for exposure summaries (summaries 1,120 requested by former Hanford employees)

4,408

8,303

Letters sent to request prior exposure (to request sunmaries for new employees with prior exposure)

Microfilm reels indexed into CAR system (personnel and historical documents. Each reel contains over 2,000 inages)

\section{Changes to the Routine Program}

During CY 1988 dose equivalent terminology was converted to "deep" and "shallow" and the recording of neutron doses less than 50 mrem was implemented. The capability to automatically load Radiation Exposure Information Reporting System (REIRS) occupational and facility codes into the ORE dosimeter results was also implemented. 


\section{Conversion of Dose Equivalent Teminology}

The external dose terminology in the ORE system was converted from penetrating, nonpenetrating, and $x$-ray dose to deep and shallow dose. Earlier Hanford dosimetry systems defined exposures as follows:

$$
\begin{aligned}
& \text { Whole Body } \\
& \text { prior to } 1962 \text { - Gama + neutrons + tritium } \\
& \text { 5-cm-depth dose for the gamma } \\
& 1962 \text { - } 1972 \text { - Gamma + neutrons + tritium + 35\% of x rays } \\
& \text { 5-cm-depth dose for the gamma } \\
& 1972 \text { - } 1987 \text { - Penetrating + neutrons + tritium } \\
& \text { 1-cm-depth dose for penetrating }
\end{aligned}
$$

Skin of the Whole Body

$$
\begin{aligned}
& \text { prior to } 1962 \text { - Whole body + beta } \\
& 1962 \text { - } 1972 \text { - Whole body + beta + 65\% of x rays } \\
& 1972 \text { - } 1987 \text { - Whole body + nonpenetrating } \\
& \text { Extremities }
\end{aligned}
$$$$
\text { All periods - Skin + ring dosimeter results }
$$

The term $x$ ray was used in the past to identify the dose from photons of $<50 \mathrm{keV}$. This dosimeter system provided doses for beta, ganma ( $>50 \mathrm{keV}$ ), and $x$-ray exposures. The $x$-ray dose was fractionated to assign $35 \%$ to the whole body and $65 \%$ to the skin. The additional 35\% of the $x$ ray was credited to the skin by using the whole body exposure as a component of the skin calculation. In 1972, the ORE database was modified to convert the ganuna to penetrating dose and the beta dose to nonpenetrating dose, and the $x$-ray dose was left to stand alone.

The conversion performed in January 1988 eliminated the former data elements--penetrating, nonpenetrating, and $x$ ray. The new data elements, shallow and deep, incorporated the following: 
Shallow - the total of the nonpenetrating, penetrating, and $100 \%$ of the $x$-ray exposure

Deep - the total of the penetrating and 35\% of the $x$-ray exposure

The old data elements were dowmloaded to a magnetic tape and placed in storage in case of future need of the data in the old format.

\section{Recording of Neutron Doses of Less Than $50 \mathrm{mrem}$}

Sonetime in the early 1980s, the ORE system was progranmed so that fast neutron doses of less than 50 mrem were not recorded for employees that were not designated as "neutron workers." This practice was in effect for only certain contractors. However, the change in the status of workers from neutron to non-neutron worker or vice versa had not always been kept up to date. Apparently, it was instituted to resolve problems with residual neutron signals on thermoluminescent dosimeters issued to non-neutron workers. In January 1988, the problen was discussed before the Hanford Personnel Dosimetry Advisory Committee. (a) It was decided that the practice should be discontinued, because the residual neutron signal was no longer a problem. The ORE database was reprogrammed so that all neutron doses are recorded.

\section{REIRS Occupational and Facility Codes}

The REIRS occupational and facility codes have previously been entered into the records manually. During 1988, the codes were loaded into the work history file from tables that were used for the 1987 reporting. Changes to the input screens have been incorporated to bring these codes into the audits when they are used for dosimeter results. This allows for the REIRS codes to be automatically loaded into the ORE dosimeter results for future REIRS reports.

(a) Fix, J. J. 1988. "Minutes of the Hanford Personnel Dosimetry Advisory Conmittee on January 14." Letter to Distribution, dated January 22, 1988. Copy in the Hanford Radiation Protection Historical File, Pacific Northwest Laboratory, Richland, Washington. 


\section{SUPPORTING TASKS}

Several tasks were completed to improve the records systems or make modifications to meet changing needs.

Redevelopment of the ORE System

The present ORE system has been in operation for over 5 years and was under development for over 2 years. It has been continuously modified and expanded. The Hanford contractors are requesting more services and the new DOE 5480.11 (1989) will require significant changes. User needs have outgrown the capabilities of the system and it is costly, in both time and money, to incorporate changes. There are no plans to upgrade the UNIVAC System D and its continued availability is in doubt.

The 1988 effort developed a preliminary plan for redeveloping the system. The report "Occupational Radiological Exposure System Study" (a) was completed and submitted to the records program. The report recomnends that the ORE system be redeveloped. Systems proposed for consideration are FLOW GEMINI, INGRESS, and a new release of ORACLE. The report was reviewed by the Hanford Dosimetry Computer Integration Comittee and they concurred with its recommendations. It is expected to take over 2 years to redevelop the ORE system.

Due to budget constraints, the redevelopment effort will not be pursued during FY 1989.

Modifications to the ORE System - Excreta Collection Addresses

In response to contractor requests, the ORE database was modified to enable contractors to access the routine excreta schedules. This access allows for contractors to confirm the schedules and the data, such as bioassay kit delivery addresses, prior to transferring the schedules to the analytical laboratory for collection of the samples. This modification provides a more effective operation for the contractors and personne? dosimetry.

(a) Johnson, K. K. 1988. Occupational Radiation Exposure System Study. Copy in the Hanford Radiation Protection Historical Files, Pacific Northwest Laboratory, Richland, Washington. 
Centralization of the Hanford Radiological Incident File

A centralized file of Hanford radiological incidents since 1945 was compiled. A search of a number of files and sources was conducted to locate as many of the incidents as possible. Copies or originals of all identified radiological incidents were placed in a chronological file in the records library. 


\section{REFEREMCES}

American National Standards Institute (ANSI). 1972. Practice for Occupational Radiation Exposure Records Systems. ANSI N13.6-1972, New York, New York.

Anerican National Standards Institute (ANSI). 1978. Radiation Protection Instrumentation Test and Calibration. ANSI N323-1978, New York, New York.

Australian Radiation Protection Society. 1988. Radiation Protection Practice. Vols 1, 2, 3, Pergamon Press, Sydney, Australia.

Bih1, D. E., T. P. Lynch, E. H. Carbaugh, and M. J. Sula. 1988. Methods to 1mprove Routine Bioassay Monitoring for Freshly Separated, Poorly Transported Plutonium. PNL-6695, Pacific Northwest Laboratory, Richland, Washington.

Dolphin, G. W., and I. S. Eve. 1963. "Some Aspects of Radiostrontium Dosimetry." Physics in Medicine and Biology 8(2):205-214.

Freedom of 1nformation Act, Public Law 89-487, July 4, 1966.

Healy, J. W. 1957. "Estimation of Plutonium Lung Burden by Urine Analysis." American Industrial Hygiene Association Quarterly 18(3):261-266.

International Comission on Radiological Protection (ICRP). 1979. Limits for Intakes of Radionuclides by Workers. ICRP Publication 30, Part 1 and Supplements, Pergamon Press, New York, New York.

Johnson, J. R., and M. B. Carver. 1981. "A General Model for Use in Internal Dosimetry." Health Physics 41:341-348.

Jones, S. R. 1985. "Derivation and Validation of a Urinary Excretion Function for Plutonium Applicable Over Tens of Years Post 1ntake." Radiation Protection Dosimetry $11(1): 19-27$.

Los Alamos Scientific Laboratory. 1981. The Los Alamos Personnel and Area Criticality Dosimeter Systems. LA-8848-MS, Los Alamos, New Hexico.

Lyon, M., J. J. Fix, J. L. Kenoyer, J. A. Leonowich, H. E. Palmer, and M. J. Sula. 1988. Hanford Radiological Protection Support Services Annual Report for 1987. PNL-6624, Pacific Northwest Laboratory, Richland, Washington.

Privacy Act, 44 Fed. Reg. 510772 (1974).

U.S. Department of Energy (DOE). 1980. Micrographics Management. DOE 1300.1, Washington, D.C.

U.S. Department of Energy (DOE). 1981a. Environmental Protection, Safety, and Health Protection Program for DOE Operations. DOE 5480.1, Washington, D.C. 
U.S. Department of Energy (DOE). 1986. Department of Energy Standard for the Performance Testing of Personnel Dosimetry Systems. DOE/EH-0027, Washington, D.C.

U.S. Department of Energy (DOE). 1987a. Department of Energy Laboratory Accreditation Program for Personnel Dosimetry. DOE 5480.15, Washington, D.C.

U.S. Department of Energy (DOE). 1987b. Environmental Protection, Safety, and Health Protection Information Reporting Requirements. DOE 5484.1, change dated June 15, 1987, Washington, D.C.

U.S. Department of Energy (DOE). 1987c. Environmental Protection, Safety, and Health Protection Reports. DOE 5484.1, Change 3, Washington, D.C.

U.S. Department of Energy (DOE). 1988. Records Disposition. DOE 1324.2, Washington, D.C.

U.S. Department of Energy (DOE). 1989. Radiation Protection for Occupational Horkers. DOE 5480.11, Washington, D.C.

U.S. Department of Energy-Richland Operations Office (DOE-RL). 1983. Hanford Site Services Handbook. RLPI 9-50.5, Richland, Hashington.

U.S. Department of Energy, Richland Operations Office (DOE-RL). 1986.

Requirements for Radiation Protection. RL 5480.11A, Richland, Washington. 
PNL -6952

UC -41

\section{DISTRIBUTION}

No. of

Copies

\section{OFFSITE}

2 DOE/Office of Scientific and Technical Information

DOE Albuquerque Operations office

J. W. Doty

Mound Laboratory

Monsanto Research Corporation

P.0. Box 32

Miamisburg, OH 45342

G. L. Potter

Rockwell International

Rocky Flats Plant

P.0. Box 2928

Golden, CD 80401

A. M. Valentine

Los Alamos National Laboratory

P.0. Box 1663

Los Alamos, NM 87545

DOE Idaho Operations Office

T. F. Pointer

Westinghouse Idaho Nuclear Company, Inc.

P.0. Box 4000

Idaho Falls, ID 83403

DOE Nevada Operations Office
No. of

Copies

DOE Oak Ridge Operations

office

J. S. Bogard

Oak Ridge National Laboratory

Martin Marietta Energy Systems, Inc.

P.0. Box 2008

Oak Ridge, TN 37831

J. B. Hunt

Y-12 Plant

Martin Marietta Energy Systems, Inc.

P.0. Box 2009

Oak Ridge, TN 37831

DOE San Francisco Operations

office

C. T. Prevo

Lawrence Livermore National Laboratory

P.0. Box 808

Livermore, CA 94550

DOE Savannah River Operations office

W. C. Reinig

E. I. du Pont de Nemours \& Co. Savannah River Plant

Aiken, SC 29809 
No. of

Copies

ONSITE

5 DOE Richland Operations Office

D. L. Clark

E. A. Erichsen

D. T. Evans

R. A. Holten

G. R. Yesberger

Hanford Environmental Health Foundation

M. J. Swint

Kaiser Engineers Hanford

D. J. Foust

2 Westinghouse Hanford Company

R. E. Heineman

W. A. Decker, Jr.
No. of

Copies

42 Pacific Northwest Laboratory

W. J. Bair

S. K. Ennor

L. G. Faust

D. M. Fleming

J. J. Fix (2)

D. P. Higby

G. R. Hoenes

J. R. Houston (2)

J. R. Johnson

J. L. Kenoyer (2)

J. A. Leonowich (2)

M. Lyon (10)

J. B. Martin

J. C. McDonald

I. E. Helson, Sr.

H. E. Paimer (2)

J. M. Selby

K. L. Soldat

M. J. Sula (2)

Publishing Coordination

Technical Report Files (5)

Radiation Protection Historical

Files (c/o V. L. Berndt) (2) 